\title{
GENDER DIFFERENCES IN JOB SEARCH: TRADING OFF COMMUTE AGAINST WAGE*
}

\author{
THOMAS LE BARBANCHON \\ ROLAND RATHELOT \\ ALEXANDRA Roulet
}

We relate gender differences in willingness to commute to the gender wage gap. Using French administrative data on job search criteria, we first document that unemployed women have a lower reservation wage and a shorter maximum acceptable commute than their male counterparts. We identify indifference curves between wage and commute using the joint distributions of reservation job attributes and accepted job bundles. Indifference curves are steeper for women, who value commute around $20 \%$ more than men. Controlling in particular for the previous job, newly hired women are paid after unemployment $4 \%$ less per hour and have a $12 \%$ shorter commute than men. Through the lens of a job search model where commuting matters, we estimate that gender differences in commute valuation can account for a 0.5 log point hourly wage deficit for women, that is, $14 \%$ of the residualized gender wage gap. Finally, we use job application data to test the robustness of our results and to show that female workers do not receive less demand from far-away employers, confirming that most of the gender gap in commute is supply-side driven. JEL Codes: J16, J22, J31, J64, R20.

*We thank Jérome Adda, Ghazala Azmat, Luc Behaghel, Michèle Belot, Pierre Cahuc, Xavier d'Haultfoeuille, Jeanne Ganault, Larry Katz, Philipp Kircher, Rafael Lalive, Rasmus Lentz, Paolo Masella, Emily Oster, Barbara Petrongolo, Jesse Shapiro, Etienne Wasmer; participants to the CEPR-IZA Labor Symposium, SOLE Meeting, NBER SI 2019, Mismatch-Matching Copenhagen workshop; seminar participants at Berlin, Bergen, Berkeley, Bocconi, Bologna, Brown, Cambridge, CREST, Edinburgh, EUI, INSEAD, Lausanne, Lyon-GATE, Maastricht, NYU Abu Dhabi, Paris Sud, PSE, Royal Holloway, Sciences Po, Sussex, UCL and Warwick, as well as four anonymous reviewers for helpful comments. We are grateful to Pôle Emploi, in particular Anita Bonnet, for letting us access their data. The views expressed herein are those of the authors and do not necessarily reflect those of Pôle Emploi. We are also grateful to Alan Krueger and Andreas Mueller for making the data from their survey on job seekers publicly available. The financial support of the ERC StG 758190 "ESEARCH" is gratefully acknowledged. The technology to access the data remotely is supported by a public grant overseen by the French National Research Agency (ANR) as part of the Investissements d'avenir program (ANR-10-EQPX-17 - Centre d'accès sécurisé aux données, CASD). Roulet acknowledges financial support from INSEAD, through The Patrick Cescau/Unilever

(C) The Author(s) 2020. Published by Oxford University Press on behalf of President and Fellows of Harvard College. This is an Open Access article distributed under the terms of the Creative Commons Attribution-NonCommercial-NoDerivs licence (http://creativecommons.org/licenses/by-nc-nd/4.0/), which permits non-commercial reproduction and distribution of the work, in any medium, provided the original work is not altered or transformed in any way, and that the work is properly cited. For commercial re-use, please contact journals.permissions@oup.com

The Quarterly Journal of Economics (2020), 1-46. doi:10.1093/qje/qjaa033.

Advance Access publication on October 17, 2020. 


\section{INTRODUCTION}

Several nonexclusive mechanisms have been recently put forward to explain the persistence of a gender gap in wages, such as gender differences in time flexibility (e.g., Bertrand, Goldin, and Katz 2010; Goldin 2014) and the so-called child penalty (e.g., Adda, Dustmann, and Stevens 2017; Kleven, Landais, and Søgaard 2019). This article explores a somewhat overlooked yet related aspect: gender differences in willingness to commute. Indeed, commute is a job attribute with large gender differences. In OECD countries, women on average spend 22 minutes a day commuting, while men spend 33 minutes. ${ }^{1}$ In France, after controlling for workers' observable characteristics, the gender commute gap, that is, the difference between women's and men's commute (in logs), still amounts to $-10 \%$ to $-15 \%$. Gender differentials in commute decreased over time in a similar manner as gender gaps in annual earnings or in hourly wages, even when adjusted for workers' experience, occupation, industry, and part-time status (Figure I).

In this article, we estimate how much men and women are willing to trade in terms of wage for a shorter commute and study the relationship between gender differences in this commute valuation and the gender wage gap. Hereafter, we do not take a stand on whether differences in commute valuation come from individual preferences or constraints resulting from household decisions. Average commute valuations are difficult to identify from realized labor market outcomes, because equilibrium outcomes are pinned down by marginal workers and because standard data sets do not measure all relevant job attributes and workers' productivity that may confound the wage effect of the attribute of interest (Brown 1980; Hwang, Reed, and Hubbard 1992). Moreover, frictions in the matching of workers and jobs often blur the compensating differentials of job attributes (Altonji and Paxson 1992; Bonhomme and Jolivet 2009; Rupert, Stancanelli, and Wasmer 2009). To overcome these difficulties, recent research makes use of choice experiments to directly estimate the workers' willingness to pay for particular job attributes (Flory, Leibbrandt, and List 2014; Mas and Pallais 2017; Wiswall and Zafar 2017; Maestas et al. 2018).

We also rely on incentivized elicitation of preferences by exploiting a unique feature of French institutions: when they

Endowed Fund for Research in Leadership and Diversity. All errors are our own. Le Barbanchon is also affiliated with CEPR, IGIER, IZA, and J-PAL, Rathelot with CAGE, CEPR, and J-PAL, and Roulet with CEPR.

1. See Chart LMF2.6.A in the OECD family database: http://www.oecd.org/els/family/database.htm. 

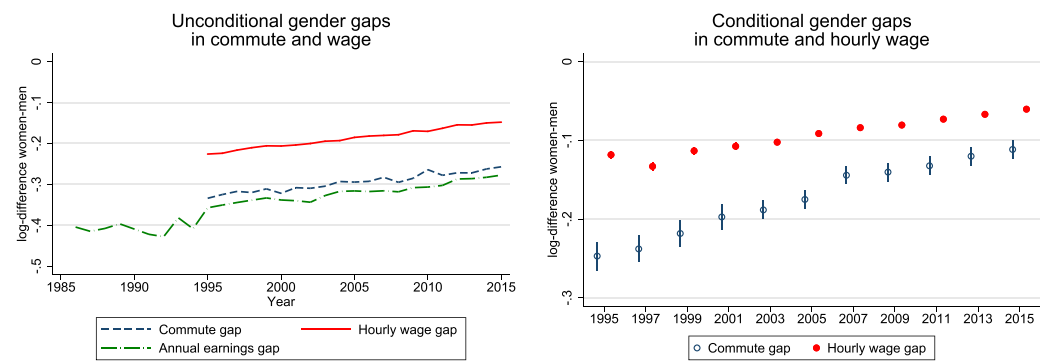

FIgURe I

Gender Gaps in Wages and Commuting Distances over Time

These figures plot the evolution of gender gaps over time, that is, the difference between women's and men's outcomes. The left panel plots the raw log-difference of the annual earnings, of the hourly wage rate, and of the commuting distance between women and men. Reliable data on commuting and hours are available since 1995. The right panel plots the adjusted gender gaps in hourly wage (red dots), and in commuting distance (blue circles). An observation is a yearly employment spell. We run separate regressions of both commuting and hourly wage every year. We include as controls age dummies, four-digit occupation dummies, experience and its square, a part-time dummy, two-digit industry dummies, and commuting zone fixed effects. Sample: $\frac{1}{60}$ sample of all private sector employment spells in France (DADS data).

register as unemployed, French job seekers must declare to the Public Employment Service (PES) the minimum wage and the maximum commute they are willing to accept. Because their statements matter for the job search services provided by the PES, they have an incentive to be attentive and answer truthfully. We thus combine the advantages in terms of incentives from field experiments such as Mas and Pallais (2017), and the large sample and external validity of administrative data.

Using a sample of around 300,000 workers, we document differences in the reservation wage and maximum acceptable commute specified by men versus women. The data are combined with matched employer-employee registers such that we can precisely control for the characteristics of the previous job and check whether these differences in reported search criteria translate into differences in the attributes of the job following the unemployment spell. We find that unemployed women have a full-time equivalent reservation wage that is $4 \%$ lower than men, controlling finely for the previous job (wage bins, three-digit occupation, etc.) and the job opportunities available (commuting zone times industry times quarter fixed effects). Women also search for jobs located closer to home. The gender gap in the maximum acceptable commute is $14 \%$ on average: from $8 \%$ for single individuals 
without children to $24 \%$ for married individuals with children. These gender differences in reservation job attributes translate into women getting paid lower wages and having a shorter commute upon reemployment.

The close connection between the gender gap in job search criteria and that observed for wages and commuting in the overall working population suggests that supply-side considerations may be an important driver of the latter. We introduce a search model where the commute matters, similar to Van Den Berg and Gorter (1997), to (i) guide our identification of whether women have steeper indifference curves between wage and commute than comparable men, and (ii) assess the extent to which the gender wage gap is accounted for by gender differences in willingness to pay (WTP) for a shorter commute. The model yields a reservation wage curve that gives for every commute the lowest wage that the job seeker is willing to accept. The slope of the reservation wage curve is equal to the WTP parameter.

Using reemployment outcomes, in deviation from the reservation wage and commute, we draw the respective acceptance frontier of jobs, separately for women and men. For non-minimum wage workers, the acceptance frontier indeed identifies the reservation wage curve. We estimate the WTP for a shorter commute for women and men and obtain that this parameter is significantly higher for women. The value of commuting time amounts to $80 \%$ of the gross hourly wage for men and $98 \%$ for women. Identification of the WTP relies on assumptions about how declared search criteria should be interpreted: for our main strategy, we assume that job seekers declare one point of their reservation wage curve to the public employment service. We check the robustness of our results to other interpretations of declared search criteria.

We feed the estimated WTP parameter for women into the job search model and calibrate the other parameters in line with our data, again for women. Keeping all these other parameters fixed, we simulate a shock that reduces WTP by $18.2 \%$, which is equal to the residualized gender difference in commute valuation that we have estimated, and look at the effect of this shock on the wage and commute in the next job. We find that gender differences in commute valuation can account for a $0.5 \log$ point hourly wage deficit for women, that is, $14 \%$ of the gender gap in residualized wages. This suggests that the contribution to the gender wage gap of gender differences in commute valuation is of the same order of magnitude as other well-studied job attributes, such as 
flexible working time and/or job security (see Wiswall and Zafar 2017, who find that gender differences in students' preferences for future earnings growth, probability of dismissal, and work hours flexibility, account for a quarter of the gender earnings gap).

Finally, we perform two robustness exercises using data from around 3 million job applications to vacancies posted at the French PES. First, we use a conditional logit model to study the effect of the commute distance between the vacancy's workplace and the worker's home on the probability of the worker applying for the vacancy. We estimate gender-specific coefficients, and include job-ad fixed effects to take care of unobserved correlated amenities. The choice model yields a significant gender gap in commute valuation of between $14 \%$ and $23 \%$, which corroborates our findings using declared search criteria. Second, we study hiring decisions by employers in response to job applications to test whether gender differences in the reservation commute could come from women internalizing a lower labor demand from faraway employers. Within-vacancy regressions show that the hiring rate decreases with the commute distance of the applicant, but not at a significantly faster rate for women. This suggests that labor demand is not more specifically tilted toward closeby candidates for women than for men. This supports our view that gender gaps in commute are primarily driven by supply-side considerations.

This article relates to several lines of research. First we bring gender differences in commuting distances into the prominent literature on the gender wage gap (Bertrand 2011; Goldin 2014; Olivetti and Petrongolo 2016; Blau and Kahn 2017). Gender differences in commuting time/distance have been documented in the urban planning (MacDonald 1999; Crane 2007) and the health and well-being literature (Stutzer and Frey 2008; Roberts, Hodgson, and Dolan 2011; Clark et al. 2019) but have not been analyzed in relation to the gender wage gap. ${ }^{2}$ Recent research on the gender wage gap provides event study evidence that the birth of the first child creates a large deterioration in how women subsequently fare in the labor market compared with men

2. In a recent paper, Petrongolo and Ronchi (2020) apply our method to estimate the WTP for a shorter commute, adapting it to British data on job-to-job transitions. The gender difference in WTP that they find has a similar magnitude to ours. Fluchtmann et al. (2020) also use application data and show that Danish women are less likely to apply for further-away jobs. 
(Angelov, Johansson, and Lindahl 2016; Kleven, Landais, and Søgaard 2019; Kleven et al. 2019). Our study sheds light on a potential mechanism for the so-called child penalty: the fact that women prefer shorter commutes, possibly to be able to drop off/pick up children from school/daycare more easily. Yet it also suggests that gender differences in the value of commute time are not only driven by children. Even among single individuals without children, we find a difference between men's and women's commute valuation that is statistically significant. Moreover, although the commute channel may have similar origins to the hours flexibility channel (Bertrand, Goldin, and Katz 2010; Goldin 2014; Goldin and Katz 2016; Bolotnyy and Emanuel 2019), we show that it contributes to the gender wage gap on top of gender differences in working hours preferences. ${ }^{3}$

Second, our article is related to the literature on compensating differentials. We bring to the literature on gender differences in compensating differentials the focus on commute valuation (Filer 1985; Mas and Pallais 2017; Wiswall and Zafar 2017; Maestas et al. 2018). We bring to prior work on the wage versus commute trade-off the focus on gender heterogeneity (Van Ommeren, Van Den Berg, and Gorter 2000; Mulalic, Van Ommeren, and Pilegaard 2014; Guglielminetti et al. 2015). ${ }^{4}$ One exception is Manning (2003), who finds in the cross section in the United Kingdom that the effect on wages of commuting is larger for women with children than for men. ${ }^{5}$ A final contribution of our article-this one methodological-is to show how data on the joint distribution of reservation job attributes and realized job bundles can be used to identify the key preference parameter for the wage versus commute trade-off. We provide

3. Our article is also related to Caldwell and Danieli (2019), who show that commute distances are an important component of the more restricted employment opportunity set for women. Our results are also in line with those of Bütikofer, Løken, and Willén (2019), who find that building a bridge between Denmark and Sweden increased commutes and wages of men more than women.

4. The large literature in transport economics on the value of travel time tends to focus on heterogeneity across income groups rather than gender differences (for a review, see Small 2012).

5. Van Ommeren and Fosgerau (2009) also find that the marginal costs of commuting are larger for women than for men, but the difference is not precisely estimated and is insignificant. 
the first estimates of the heterogeneity of this parameter across gender. ${ }^{6}$

The remainder of the article is organized as follows. Section II describes the data. Section III presents the reduced-form evidence on gender differences in job search criteria and reemployment outcomes separately. Section IV explains how the commute valuation is identified from the joint distribution of search criteria and realized outcomes and shows that women have steeper indifference curves between wage and commute than men. Section $V$ estimates the share of the gender wage gap accounted for by gender differences in willingness to pay for a shorter commute. Section VI provides further evidence of gender differences in commute valuation using application data. Section VII concludes. All appendix material can be found in the Online Appendix.

\section{DATA Description}

\section{II.A. Data Sources and Sample}

Our sample is drawn from a matched data set of French unemployment and employment registers. Information on unemployment spells derives from the fichier historique $(\mathrm{FH})$ of the French public employment service (Pôle Emploi), and that on employment spells comes from the déclarations administratives de données sociales (DADS) built by the French Institute of Statistics (Insee) from firms' fiscal declarations. Legal protection of private information allows the matching for a subpopulation with a sampling rate of 1 in 12 .

Our sample includes unemployment insurance (UI) claimants whose unemployment spell starts between 2006 and $2012 .{ }^{7} \mathrm{We}$ restrict the sample to people who lost their jobs involuntarily, be it a permanent or a temporary/fixed-term contract. We observe their employment history from 2004 to 2012, from which we define (i) the last job before unemployment (last employment spell ending before they become unemployed) and (ii) the next job after unemployment (first employment spell starting after their

6. Black, Kolesnikova, and Taylor (2014) analyze the link between commuting and labor force participation of women.

7. The year 2006 is when the search criteria variables start to be asked, and 2012 is when the merge between our two main data sets stops. We focus on new claims from the regular UI rules, excluding workers in the culture and arts industries (intermittents du spectacle) and from temporary help agencies (interimaires). 
unemployment spell starts). ${ }^{8}$ Our main sample comprises around 320,000 unemployment spells.

\section{II.B. Reservation Wage and Maximum Acceptable Commute}

When registering as unemployed in France, people are asked about the type of job they are seeking, their reservation wage, and maximum acceptable commute. ${ }^{9}$ Online Appendix Figure $\mathrm{C} 1$ is a screenshot of the online registration form. First, people are asked which occupation they are looking for. The preferred occupation may be different from their previous one. Second, in response to the reservation wage question: "What minimum gross wage do you accept to work for?," they indicate an amount and choose a unit (hourly, monthly, or annual). Third, people are asked for their maximum acceptable commute or reservation commute: "What length of daily commute (one way) would you accept?" Job seekers can reply either in minutes or in kilometers. They cannot move to the next page of the registration website without reporting this information. Before job seekers answer the questions on their desired occupation, reservation wage, and maximum commute, they state whether they are willing to accept a temporary contract or a part-time job (see the screenshot in Online Appendix Figure C2).

All this information enables caseworkers from the public employment service to select the vacancies they will propose to job seekers. ${ }^{10}$ If browsing through vacancies is costly, standard theory suggests that the best response of job seekers is to reveal their true reservation wage and other job characteristics to the PES. Moreoever we are confident that the monitoring/sanctioning role of the PES does not lead job seekers to misreport their reservation wage and commute. When monitoring the search activities of job seekers, caseworkers are legally required to compare the posted wages of vacancies to which job seekers apply to their past

8. We apply the standard restrictions in the employment registers to analyze meaningful jobs. We exclude jobs tagged as annex by the data producer. We restrict the sample to employers from the private sector.

9 . This section follows closely the description of the reservation wage data in Le Barbanchon, Rathelot, and Roulet (2019).

10. The services that the PES offers to unemployed job seekers are described in the PPAE (Projet Personnalisé d'accès a l'emploi), cf. article L5411-6-1 of the Labor Code, https://www.legifrance.gouv.fr/ affichCodeArticle.do?idArticle=LEGIARTI000037388467\&cidTexte=LEGITEXT 000006072050\&dateTexte $=20190101$ ). 
wage or the usual wage in the occupation searched for-not to their reservation wage. As for the commute, they compare it with predetermined targets ( 1 hour or 30 kilometers), not to the stated reservation commute. Whether the desired number of working hours and type of labor contract are used for monitoring/sanctions purposes is less clear. The law states that "If the desired job is full-time, job seekers cannot be forced to accept part-time jobs," which may induce UI claimants to strategically report that they are seeking a full-time job. Regarding the labor contract, there are no published/explicit guidelines. That being said, concerns of strategic reporting bias are minimal in the French context, where the PES is rated low in terms of mobility demands and sanctions relative to international standards (Venn 2012). In practice, no sanctions are imposed. Only $0.5 \%$ of unemployment spells in our sample are ended by the PES for failing to comply with jobsearch requirements. Moreover, search criteria are not significant predictors of being sanctioned (see Online Appendix Table D1). We understand that caseworkers are mostly active in their counseling role where their objective is aligned with that of the job seekers.

\section{II.C. Summary Statistics}

Table I contains the raw summary statistics from our sample. Prior to being unemployed, women earned on average $€ 1,941$ gross a month (full-time equivalent) and their average commute was 16.4 kilometers, for men it was $€ 2,087$ and 20.6 kilometers. The commute measure in the employment registers is the distance between the centroids of the municipality of the workplace and the municipality of residence. There are more than 34,000 municipalities in France, so municipality centroids proxy well for actual locations. When workers reside and work in the same municipality ( $24.7 \%$ of the sample), we proxy for their commute by the average distance between two random locations within the municipality.

The average monthly gross reservation wage (full-time equivalent) of job seekers in our sample is $€ 1,579$ for women and $€ 1,741$ for men. The maximum acceptable commute (one way) is 26 kilometers for women who report in distance and 40 minutes for women who report in time. The corresponding figures for men are 32 kilometers and 45 minutes. Close to half the sample find a job within two years. Online Appendix Table D2 reports the 
TABLE I

SUMmaRy STATISTICS

\begin{tabular}{lcc}
\hline \hline Variable & Men & Women \\
\hline Preunemployment variables & & \\
Age & 33.4 & 33.4 \\
Married & 0.371 & 0.410 \\
Child & 0.318 & 0.427 \\
Education (years) & 11.3 & 11.8 \\
Experience (years) & 6.68 & 5.62 \\
Past wage (monthly, gross, euros) & 2,087 & 1,941 \\
Past commuting distance (km) & 20.6 & 16.4 \\
Past job is full-time & 0.825 & 0.656 \\
Past contract is open-ended & 0.467 & 0.372 \\
Number of obs. & 169,041 & 150,783 \\
Search-related variables & & \\
Reservation wage (monthly, gross, euros) & 1,741 & 1,579 \\
Max commute dist. acceptable (km) & 32.1 & 25.9 \\
Max commute time acceptable (min) & 45.2 & 40.2 \\
Looking for a full-time job & 0.966 & 0.862 \\
Looking for an open-ended contract & 0.926 & 0.912 \\
Looking for same occupation (three-digit) & 0.283 & 0.288 \\
Found a job within two years & 0.480 & 0.456 \\
Nonemployment duration (days) & 426 & 431 \\
Number of obs. & 169,041 & 150,783 \\
Reemployment outcomes & & \\
Next-job wage (monthly, gross, euros) & 1,947 & 1,825 \\
New commuting distance (km) & 21.3 & 16.6 \\
Next job is full-time & 0.841 & 0.712 \\
Next-job contract is open-ended & 0.377 & 0.343 \\
Finding in same occupation as prev. job & 0.262 & 0.304 \\
Number of obs. & 81,162 & 68,744 \\
\hline \hline
\end{tabular}

Notes. The sample consists of workers starting an unemployment spell between 2006 and 2012 (subsample from FH-DADS). Child indicates whether workers have at least one child. Wages are full-time-equivalent gross monthly wages. Commuting distances are for one-way trips. Looking for same occupation is a dummy for whether workers state as their desired occupation the occupation of their preunemployment job. Finding in same occupation is a dummy for whether workers' occupation in their new job is the same as their occupation in their preunemployment job.

summary statistics of preunemployment variables and search criteria for this subsample of job finders.

Figure II plots the distribution of our main variables of interest. The four panels are restricted to people who found a job within two years to keep the same sample whether we look at reemployment outcomes or reservation job characteristics. Panel A shows the reservation wage, divided by the previous wage. Four out of 
(A) Reservation wage over previous wage

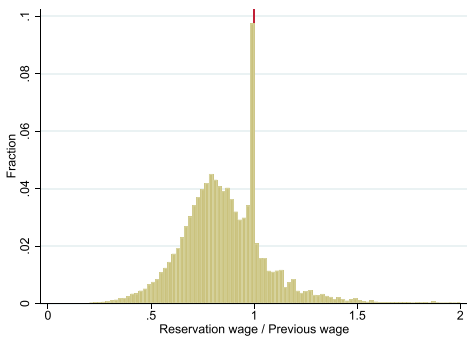

(C) Maximum acceptable commute over previous commute

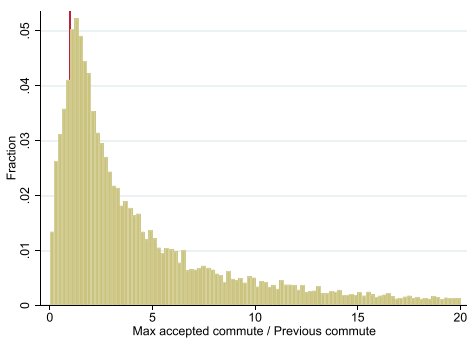

(B) Reemployment wage over reservation wage

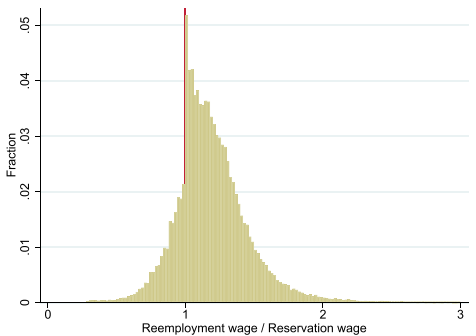

(D) Reemployment commute over maximum acceptable commute

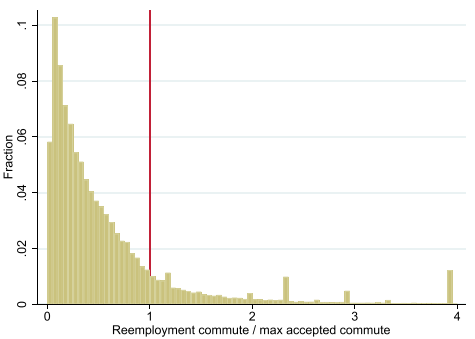

FIGURE II

Distribution of Search Criteria, Relative to Previous and Next Jobs

These figures plot the distributions of search criteria and employment outcomes for our main sample of unemployed people restricted to those who find jobs within two years. Panel A plots the distribution of the ratio of the unemployed's reservation wage over the wage in her previous job (both FTE gross monthly). Panel B plots the ratio of the reemployment wage (also FTE gross monthly) over the reservation wage. Panel $\mathrm{C}$ plots the ratio of the maximum acceptable commute (in $\mathrm{km}$ ) over the commuting distance in her previous job. Panel D plots the ratio of the reemployment commuting distance over the maximum acceptable commute (in $\mathrm{km}$ ). The sample in Panel $\mathrm{C}$ and $\mathrm{D}$ is further restricted to workers stating their maximum acceptable commute in kilometers when they answer the PES questions.

five workers specify a reservation wage lower than their previous wage. The excess mass at 1 reflects the fact that $12 \%$ of our sample anchor their reservation wage on their prior wage. This is mostly driven by minimum-wage workers, as shown in Online Appendix Figure C3. Panel B of Figure II shows the reemployment wage divided by the reservation wage. Eighty-one percent of workers find a job above their reservation wage. Panel $\mathrm{C}$ shows the reservation commute divided by the commute in the previous 
job. Most job seekers (91\%) report a maximum acceptable commute greater than their previous commute. Panel D shows the commute on reemployment divided by the reservation commute: $81 \%$ of unemployed individuals end up commuting less than their reservation commute.

To further describe these variables, we plot in Online Appendix Figure C4 the raw distributions of monthly reservation wages and maximum acceptable commutes. They illustrate that workers do not answer some default option or very round numbers. This suggests that workers pay attention to their answers. Moreover, Online Appendix Table D4 shows how job search criteria predict job-finding rates. We see that a larger maximum acceptable commute increases the job-finding rate, while a higher reservation wage reduces it, controlling for the characteristics of the previous job and workers (including age, education, marital, and parental status). This suggests that the search criteria measures do capture some meaningful information that corresponds to the theoretical notion of a reservation wage and of a reservation commute.

\section{Gender Differences in Job Search Criteria And REEMPLOYMENT OUTCOMES}

In this section, we document how job search criteria and reemployment outcomes vary across gender. We first estimate average gender gaps in reservation and accepted job attributes. Second, we document the heterogeneity in gender gaps by family structure, by worker's age, and by geography. Third, we provide evidence in support of the external validity of our results, by looking at jobto-job transitions and by using survey data on U.S. job seekers.

\section{III.A. Average Gender Gaps in Reservation Wage and Commute and in Reemployment Outcomes}

We first estimate gender gaps in reservation wage and in reservation commute. Table II shows results from regressions of a reservation job attribute on a female dummy. In columns (1), (3), and (5), the outcome is the reservation wage in logs, while in columns (2), (4), and (6) it is the maximum acceptable commute, also in logs. In columns (1) and (2), we control for worker characteristics (age dummies, years of education dummies, marital status, parenthood, and work experience), for the characteristics 


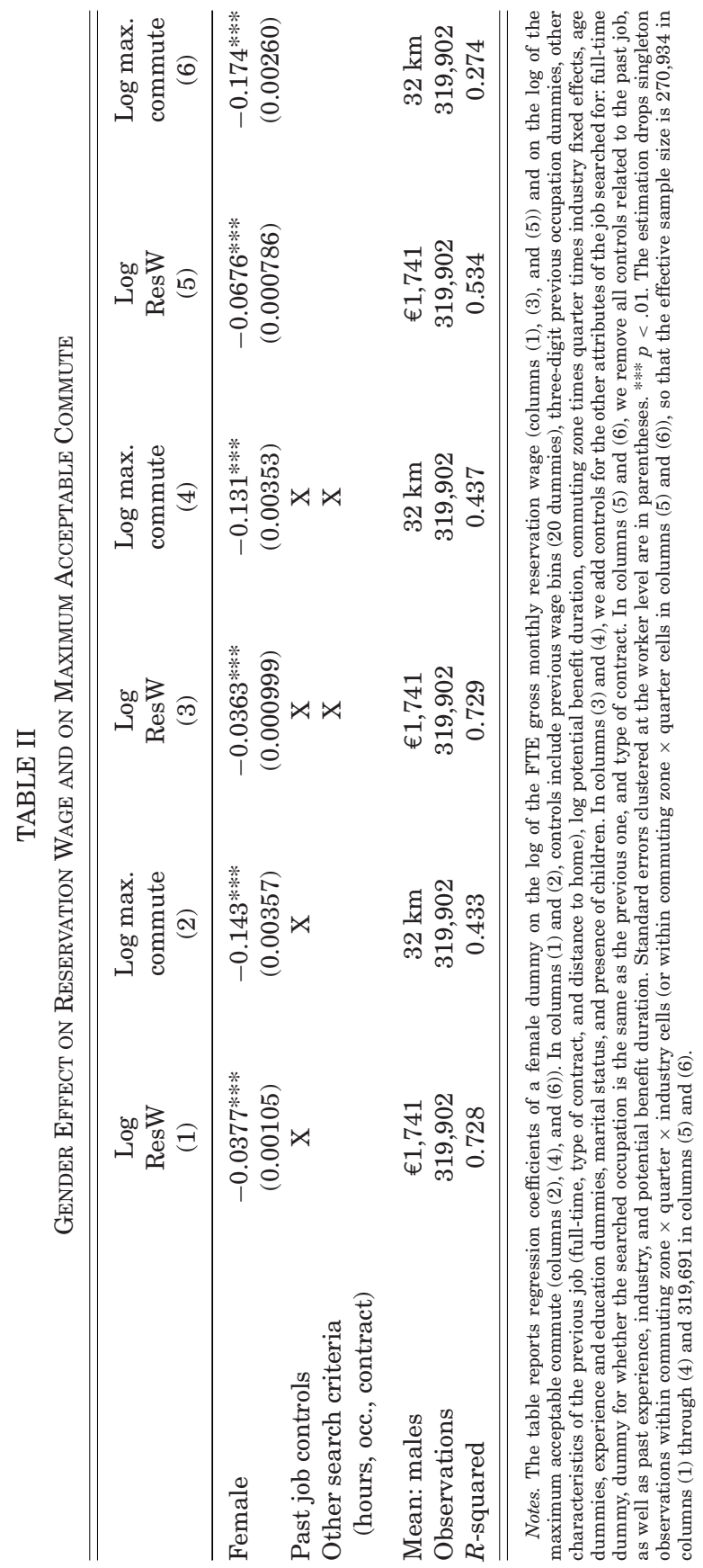


of the previous job (full-time equivalent wage in 20 bin dummies, three-digit occupation dummies, previous hours, type of contract, and distance to home), for the log of the potential benefit duration (UI generosity), and for the units of declaration for the reservation wage and for the maximum commute questions. We also control for local labor market conditions with commuting zone times two-digit industry times unemployment registration quarter fixed effects. Columns (3) and (4) add further controls for other dimensions of reported job preferences: dummies for whether the desired occupation is the same as the previous one, whether the person is looking for a full-time job, and whether she is willing to accept a temporary job. In columns (5) and (6), we remove all controls related to the previous job, as well as past experience, industry, and potential benefit duration. Our preferred estimates are in columns (1) and (2), but because we are controlling very finely for the previous job, including detailed occupation, previous wage, and commute, there is a potential concern of overcontrolling. The gaps in columns (1) and (2) may be seen as lower bounds while the estimates of columns (5) and (6) would be upper bounds. At the end of our analyses, when we document what share of gender gaps is explained by differences in commute valuation, we will consider these two alternatives in terms of controls.

Table II provides evidence that women are less demanding than men on the wage dimension but more demanding on the commute dimension. In our preferred specification, women specify a $4 \%$ lower reservation wage than men, while their stated maximum acceptable commute is $14 \%$ lower than that of comparable men. Online Appendix Table D3 reports gender differences in occupation and working hours. Women and men have almost the same propensity to search for a job in the same occupation as the one they held previously (the gender gap is less than 0.7 percentage points). Consistent with previous research, women have a higher propensity to look for a part-time job than men-by 6.5 percentage points. Hence columns (3) and (4) test whether the gender gaps in reservation wage and in reservation commute survive when we control for the difference in preferred working hours. We find that they are barely affected by gender differences in the preference for part-time work. Columns (5) and (6) show that removing all controls related to the previous work history (and other search criteria) increases the gap to $7 \%$ for the reservation wage and $17 \%$ for the reservation commute.

Table III shows that gender gaps in reemployment outcomes closely follow the gender gaps in search criteria. Even when 


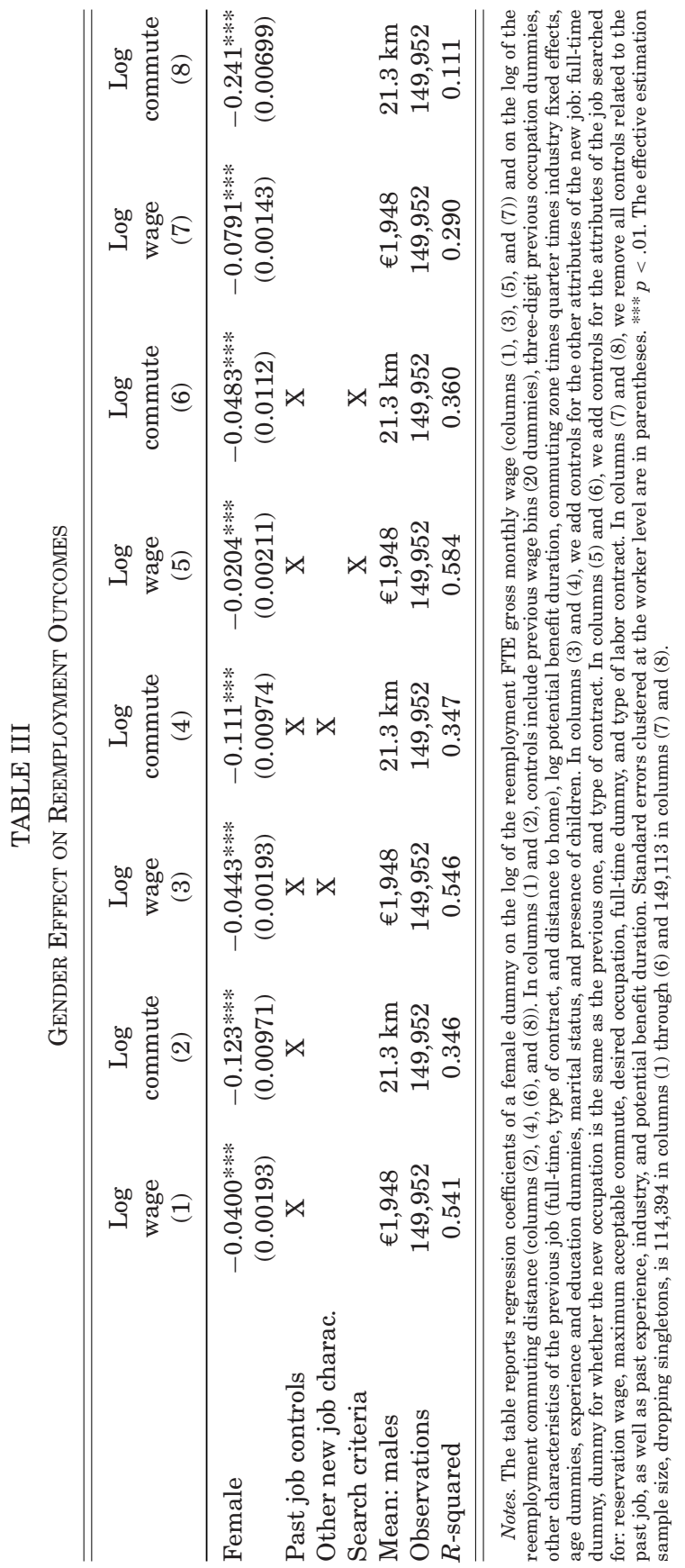


controlling finely for the previous job characteristics, the gender wage gap amounts to $4 \%$ (column (1)), and the gender commute gap to $12 \%$ (column (2)). These differences survive when we control for other attributes of the new job in columns (3) and (4): part-time, type of contract, and change of occupation. In columns (5) and (6), we control for the search criteria (reservation wage, maximum acceptable commute, and others). With the search-related controls, magnitudes are roughly halved: the gender wage gap amounts to $2 \%$ and the gender commute gap to $5 \%$. Columns (7) and (8) show that the gender gaps double when removing all controls related to the previous work history to $8 \%$ for wages and $24 \%$ for commuting distances. The parallel between Tables II and III builds confidence in the validity of the answers to the search strategy questions asked by the French PES. Moreover, it suggests that gender gaps in realized job outcomes are partly driven by labor supply. This is further hinted at in the heterogeneity analyses in Section III.B.

By construction, the sample in Table III-containing only job seekers who found a job within two years-is a subset of that of Table II. Online Appendix Table D4 rules out major differential selection into employment across gender. Without controlling for the type of job looked for, but controlling precisely for the previous job characteristics, the probability of women finding a job within two years is 2.4 percentage points lower than that of men. This difference becomes insignificant when we control for all the characteristics of the job sought.

1. Flexibility in Working Hours. From a theoretical perspective, individuals with a high value of nonworking time should value both a short commute and working-hours flexibility. In Table II, column (4), we show that women state a preference for shorter commutes on top of their preference for part-time jobs, by controlling for preferred hours. In Panel $\mathrm{C}$ of Online Appendix Table D3, we estimate gender gaps in search criteria, restricting the sample to job seekers who previously held a full-time job and who are likely to hold similar preferences for workinghours flexibility. We find an average gender gap in the maximum acceptable commute of a similar magnitude as for the whole sample.

2. Mobility Decisions. Willingness to commute might also interact with residential mobility decisions, raising a concern that 
these decisions do not affect men and women similarly, which could introduce some biases in gender gaps estimates. Around $15 \%$ of job seekers change municipality between their initial registration at the PES (when they declare their search criteria) and their next job. We find no gender differences in this proportion, neither conditional on our set of controls nor unconditionally. However reemployment commute depends on residential mobility: among men, commute is $15 \%$ shorter for those who moved, whereas among women it is $4 \%$ shorter for those who moved. The gender difference in commute is thus smaller for movers. Including movers in our analysis attenuates the gender commute gap estimate but the magnitude of the difference is small (see Online Appendix Table D5, Panel D).

3. Residential Sorting. In the main analysis, we introduce commuting zone fixed effects to control for local labor market conditions. In Online Appendix Table D6, we further control for municipality fixed effects. This barely affects the gender gaps in the reservation wage and commute, and in the reemployment wage and commute.

\section{III.B. Heterogeneity by Family Structure, Age, and Geography}

1. Heterogeneity by Family Structure. In Figure III, we report gender differences by marital status and the presence of children. These gender gaps are obtained by interacting the gender dummy with the interaction between marital status and the presence of at least one child in specifications similar to that of Tables II and III. Online Appendix Table D7 reports the detailed estimation results. The upper left panel of Figure III shows that the gender gap in reservation wages is larger for married job seekers and parents: married mothers have a 6\% lower reservation wage than do married fathers. Interestingly, there is still a $2 \%$ gap among single individuals without children. Similarly, the bottom-left panel shows that the gender gap in the reservation commute increases with family size. While single women without children are willing at most to commute $8 \%$ less than comparable men, the difference increases to around $18 \%$ for either married workers without children or single workers with at least one child and to even $24 \%$ for married workers with at least one child.

The right panels report the same heterogeneity analyses for wages and commutes in the general population. For these panels, we use a sample of the employer-employee registers (DADS) 
(A) Reservation wage

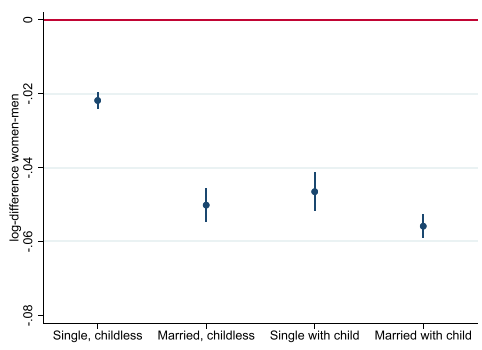

(C) Maximum acceptable commute

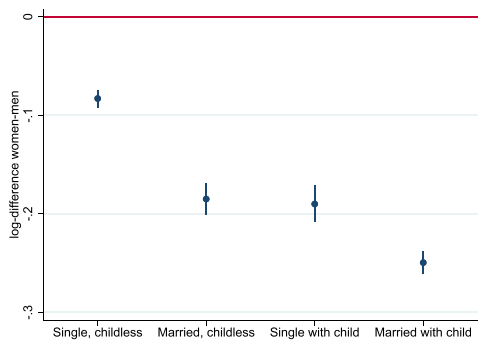

(B) Wage

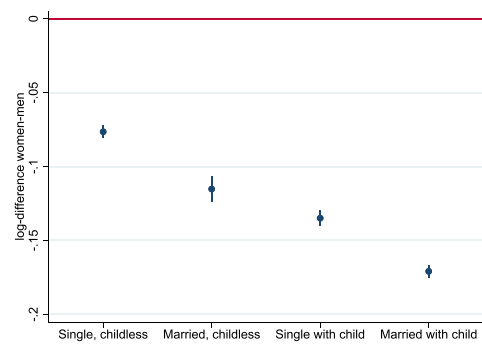

(D) Commute

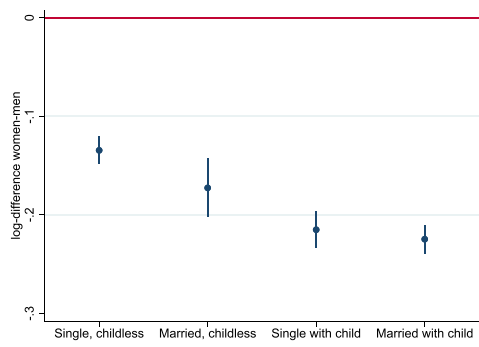

FIGURE III

Gender Gaps Grow with Family Size

These figures plot regression coefficients of a female dummy interacted with different household structure dummies, on the log of the FTE gross monthly reservation wage (Panel A), the log of FTE gross monthly wages (Panel B), the log of the maximum acceptable commute (Panel $\mathrm{C}$ ), and the log of commute (Panel D). Search criteria analyzed in Panels A and C are based on our main sample comprising 319,000 job seekers. Realized wages and commutes in Panels $\mathrm{B}$ and D come from a sample of $4 \%$ of all private sector yearly employment spells in France between 2003 and 2010 (DADS-EDP data). We control for education, age, marital status, children, experience, and year $\times$ industry $\times$ CZ fixed effects. When analyzing search criteria, we also control for potential benefit duration, and previous job characteristics (contract, hours, occupation, and wage bins). When analyzing realized outcomes, we include a part-time dummy and occupation dummies. Vertical lines for $95 \%$ confidence intervals.

\section{matched with vital statistics (EDP), without restricting to the data matched with unemployment registers. We also find that gender gaps increase with family size. ${ }^{11}$}

11. In Online Appendix Table D8, we perform the same heterogeneity analyses for the reemployment wage and commute in our main sample of job seekers. We also find that gender gaps increase with family size, though at a slower pace than for attributes of the job searched for. 
(A) Reservation wage

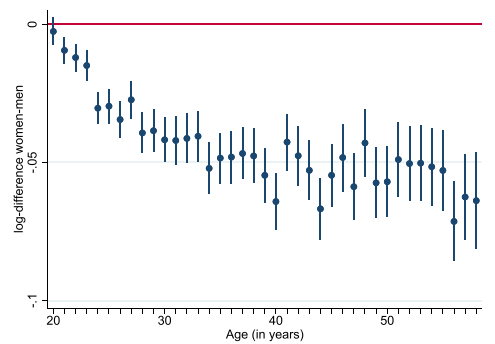

(C) Maximum acceptable commute

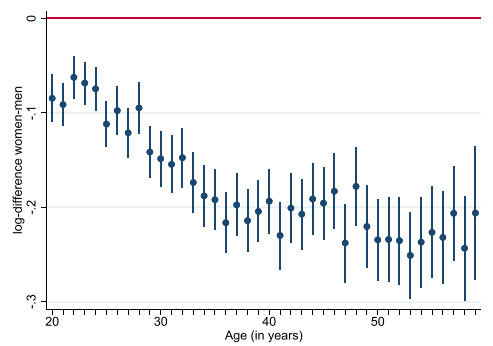

(B) Wage

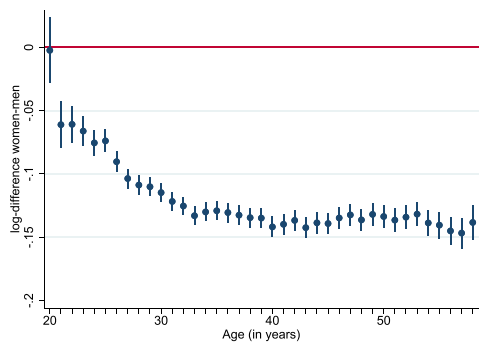

(D) Commute

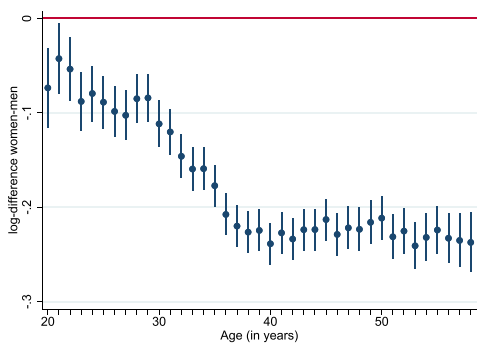

Figure IV

Gender Gaps Grow with Age

These figures plot regression coefficients of a female dummy interacted with age dummies, on the log of the FTE gross monthly reservation wage (Panel A), the log of FTE gross monthly wages (Panel B), the log of the maximum acceptable commute (Panel C), and the log of commute distances (Panel D). Search criteria analyzed in Panels A and C are based on our main sample comprising 319,000 job seekers. Realized wages and commutes in Panels B and D come from a sample of $4 \%$ of all private sector yearly employment spells in France between 2003 and 2010 (DADS-EDP data). We control for education, age, marital status, children, experience, and year $\times$ industry $\times$ CZ fixed effects. When analyzing searched criteria, we also control for potential benefit duration, and previous job characteristics (contract, hours, occupation, wage bins). When analyzing realized outcomes we include a part-time dummy and occupation dummies. Vertical lines are $95 \%$ confidence intervals.

2. Heterogeneity with Respect to Age. The left panels of Figure IV show that gender gaps in reservation wage and commute grow with age until the age of 40 and then begin to plateau, following a pattern quite similar to that documented in the right panels for the gender wage and commute gaps in the overall working population. In Online Appendix Figure C5, we check that these age effects are not confounded by cohort effects. 
3. Heterogeneity by Geography. Online Appendix Figure C6 shows the heterogeneity in the gender gaps between the Paris region and the rest of France. There is a large heterogeneity in transportation modes between these two zones. Indeed, using survey data from the French statistical agency (Insee) on mode of transportation for commute (Mobilités professionnelles survey), we find that the share of people who commute by public transport in the Paris region is on average $43 \%$, whereas in the rest of France this share is on average 7\%. In Online Appendix Figure C6, we see that gender gaps in reservation/realized wages and commute are significantly larger outside of the Paris region, where a worker's main option for commute is driving.

\section{III.C. External Validity}

Online Appendix Table D10 reports estimates of the gender gap in reservation wages found in other studies, for the United States, the United Kingdom, and Germany (e.g., Feldstein and Poterba 1984; Brown, Roberts, and Taylor 2011; Caliendo, Lee, and Mahlstedt 2017). Although the majority of these studies are not focused on the gender gap, they report coefficients of a gender dummy in Mincerian regressions of reservation wages. Women in the United States, in the United Kingdom, and in Germany also state lower reservation wages than comparable men. The order of magnitude of these gaps is comparable to our findings for France, but our administrative data on labor market outcomes and reservation wages yield estimates that are much more precise than in previous literature. To the best of our knowledge, no comparable studies report gender gaps in other dimensions of job search, although the survey of Krueger and Mueller (2016) asks workers about their willingness to commute. We use these data made publicly available by the authors to compute the gender gap in desired commute time in the United States (which, to our knowledge, has not been analyzed so far). Table IV shows that U.S. women search for jobs that can be reached with $26 \%$ less commuting time.

We have provided evidence on gender differences in preferences of the unemployed and in job characteristics after a period of unemployment, but do we observe similar patterns for job-to-job transitions? In Online Appendix Table D11, we report the results of the same regression as in Table III for the population of employed workers switching jobs. The gender gaps in the new wage and commute are very close to what is observed for unemployed 
TABLE IV

Gender Effect on the Reservation Wage and Maximum Acceptable Commute IN THE UNITED STATES

\begin{tabular}{lcc}
\hline \hline & $\begin{array}{c}\text { Log } \\
\text { ResW } \\
(1)\end{array}$ & $\begin{array}{c}\text { Log max } \\
\text { commute } \\
(2)\end{array}$ \\
\hline Female & $-0.0889^{* * *}$ & $-0.258^{* * *}$ \\
& $(0.0168)$ & $(0.0365)$ \\
Mean: males & $\$ 20.13$ & $46.8 \mathrm{~min}$ \\
Observations & 3,662 & 3,918 \\
$R$-squared & 0.625 & 0.186 \\
\hline \hline
\end{tabular}

Notes. Sample: Survey of Unemployed Workers in New Jersey (see Krueger and Mueller 2016). The table reports regression coefficients of a female dummy on the log of the hourly reservation wage (column (1)) and on the log of the maximum acceptable commute (column (2)). For the sake of comparability to Table 1 in Krueger and Mueller (2016), the sample is restricted to the first interview of each worker. Controls are the same as in column (3) of Table 1 in Krueger and Mueller (2016) (except for nonpublicly available administrative data on UI and past wage levels). Controls include age groups, education groups, potential experience and its square, marital and couple status, number of children, ethnicity and race, previous household income, spouse employment, savings, liquidity access, previous job characteristics (full-time, tenure, and its square), unemployment duration, severance payments received, stated risk preferences, patience proxy and declaration unit for reservation wages. Survey weights are used. Standard errors are robust. ${ }^{* * *} p<.01$.

job seekers. This suggests that focusing on unemployed workers is informative about gender differences in job preferences of the whole working population.

Overall, this section has provided evidence of substantial gender gaps in the reservation wage and reservation commute, as well as similar gaps in accepted commute and wage. All gaps grow wider with age and family size, suggesting that labor supply adjusts differently for men and women over their working life cycle. We hypothesize that these gender gaps are partly driven by gender differences in commute valuation. Women have a higher willingness to pay for a shorter commute than men, which translates into a lower reservation wage and commute and results ultimately in a lower reemployment wage and commute. In the next section, we provide estimates of the gender differences in commute valuation.

\section{Gender Difference in Commute Valuation}

The aim of this section is to quantify the gender gap in willingness to pay for a shorter commute. Commute valuation is identified from the joint distributions of the reservation wage and commute and of the accepted wage and commute. This is not straightforward, as it requires assumptions about what job seekers understand when they declare their reservation wage and 
maximum acceptable commute. We first introduce a job search model that allows us to be explicit and to formalize these choices.

\section{IV.A. A Search Model Where Commuting Matters}

We consider a random job search model where commuting matters (Van Den Berg and Gorter 1997). The instantaneous utility of being employed in a job with log-wage $w=\log W$ and commute $\tau$ is given by $u(W, \tau)=\log W-\alpha \tau$. The parameter $\alpha$ measures the willingness to pay for a shorter commute and may differ between men and women. This is the key preference parameter we want to identify. It can be thought of as an individual preference/cost parameter or as a reduced-form parameter that is the outcome of household bargaining on gender task specialization.

Job matches are destroyed at the exogenous rate $q$. While unemployed, workers receive flow utility $b$ and draw job offers at the rate $\lambda$ from the cumulative distribution function of log-wage and commute $H$. The job search model admits a standard solution, which is summarized in the following Bellman equation for the unemployment value $U$ :

$$
r U=b+\frac{\lambda}{r+q} \int_{0}^{\infty} \int_{0}^{\infty} \mathbf{1}_{\{w-\alpha \tau>r U\}}(w-\alpha \tau-r U) d H(w, \tau),
$$

where $r$ is the discount rate.

Job seekers accept all jobs that are such that $w-\alpha \tau>r U$. For a job next door, that is, when $\tau=0$, the reservation log-wage is $\phi(0)=r U$. For a commute $\tau$, the reservation log-wage is: $\phi(\tau)=$ $r U+\alpha \tau$. This allows us to define a reservation log-wage curve:

$$
\phi(\tau)=\phi(0)+\alpha \tau
$$

The reservation log-wage curve follows the indifference curve in the log-wage/commute plane with utility level $r U$. Note that the slope of the reservation log-wage curve is the parameter $\alpha$, so that identifying the reservation curve yields the willingness to pay for a shorter commute. Replacing $r U$ by $\phi(0)$ in the Bellman equation, we obtain the solution for the intercept of the reservation log-wage curve:

$$
\phi(0)=b+\frac{\lambda}{r+q} \int_{0}^{\infty} \int_{\phi(0)+\alpha \tau}^{\infty}(w-\phi(0)-\alpha \tau) d H(w, \tau) .
$$


This solves the model. For the sake of completeness, we express the average commute and log-wage in the next job, $E\left(\tau^{n}\right)$ and $E\left(w^{n}\right)$ :

$$
E\left(\tau^{n}\right)=\frac{1}{p} \int_{0}^{\infty} \int_{\phi(0)+\alpha \tau}^{\infty} \tau d H(w, \tau)
$$

$$
E\left(w^{n}\right)=\frac{1}{p} \int_{0}^{\infty} \int_{\phi(0)+\alpha \tau}^{\infty} w d H(w, \tau),
$$

where $p=\int_{0}^{\infty} \int_{\phi(0)+\alpha \tau}^{\infty} d H(w, \tau)$ is the probability of accepting a job offer.

\section{IV.B. Identifying the Commute Valuation}

To identify the parameter $\alpha$, the willingness to pay for a shorter commute, we need to relate the search criteria measures to variables in the model. The PES question about the reservation wage does not explicitly anchor the commute dimension. Symmetrically, the question about the maximum acceptable commute does not specify the wage to consider. Without further information, we may consider two main interpretations:

- Interpretation 1: Job seekers answer a pair $\left(\tau^{*}, \phi^{*}\right)$ of job attributes that lies on their reservation wage curve, so that $\phi^{*}=\phi(0)+\alpha \tau^{*}$.

- Interpretation 2: Job seekers report the reservation wage $\phi(0)$ corresponding to the minimum possible commute (0) and the reservation commute $\phi^{-1}(\bar{w})$ corresponding to the largest wage they could get, $\bar{w}$.

Interpretation 2 differs from Interpretation 1 in that it implies that workers do not accept jobs that are both close to their reservation wage and close to their maximum acceptable commute (see Online Appendix Figure C7 for an illustration of these two interpretations). Figure $\mathrm{V}$ shows the joint density of reemployment wage and commute, relative to the reservation wage and commute, for men (upper panel) and women (lower panel). By construction, the plot is restricted to workers finding jobs. ${ }^{12}$ Consistent with the job search model, most of the density mass is in the upper

12. We convert the maximum commuting time for those who declare in minutes into kilometers, assuming that average commuting speed is $35 \mathrm{~km} / \mathrm{hour}$. 


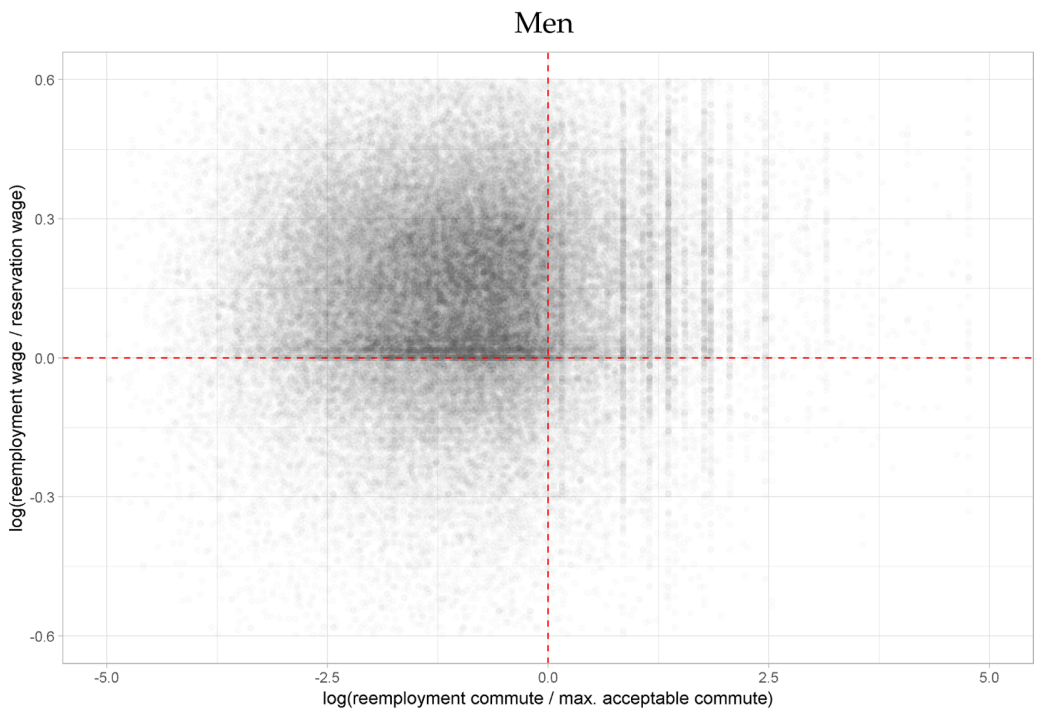

Women

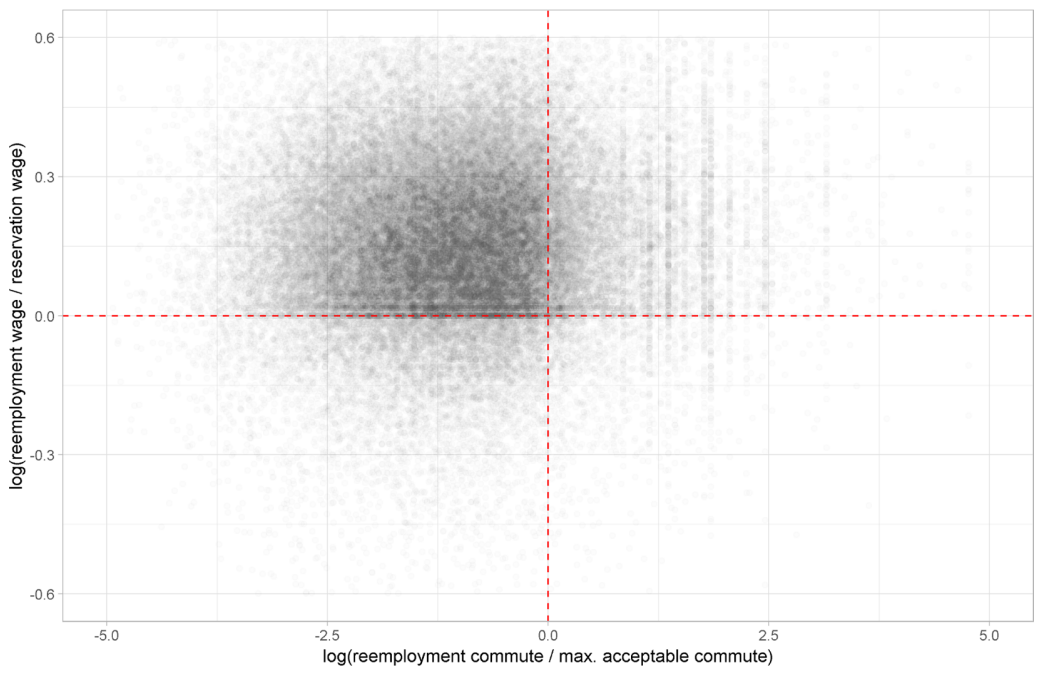

Figure V

Characteristics of Next Job Relative to Search Criteria for Men (Upper Panel) and for Women (Lower Panel)

The figure plots the joint density of the log reemployment wage and commute in deviation from the reservation wage and commute. The vertical dashed red line shows where the reemployment commute equals the maximum acceptable commute. On the horizontal dashed red line, the reemployment wage equals the reservation wage. When job seekers report their reservation commute in minutes, we convert their answers in kilometers using a speed equal to $35 \mathrm{~km} / \mathrm{h}$. 
left quadrant: workers accept jobs paying more than their reservation wage and closer to home than their reservation commute. Importantly, we do not observe the missing mass predicted by Interpretation 2 in the bottom right corner of the upper left quadrant, where the accepted jobs are both just above the reservation wage and just below the maximum acceptable commute. This is true for both men and women. Figure V provides suggestive evidence in favor of Interpretation 1. We adopt Interpretation 1 in our main analysis, and we provide a robustness analysis under Interpretation 2 in Online Appendix A. In Online Appendix A, we also consider a variant of Interpretation 2 (denoted Interpretation 2 bis), where job seekers report the reservation wage $\phi\left(\tau_{25}\right)$ corresponding to the first quartile of potential commute and the reservation commute $\phi^{-1}\left(w_{75}\right)$ corresponding to the third quartile in the potential wage distribution. ${ }^{13}$

To identify the reservation log-wage curve, we leverage the theoretical insight that accepted job bundles are above the reservation wage curve in the commute/wage plane. As a consequence, the frontier of the convex hull of accepted jobs draws the indifference curve delivering the reservation utility. This result holds under some regularity conditions for the job offer distribution. The job offer probability density function must be bounded from below, so there is no region of the commute/wage plane where the acceptance strategy is degenerate and thus less informative.

The identification strategy of the WTP for a shorter commute $\alpha$ proceeds in two steps. First, under Interpretation 1, reservation curves pass through the point where the job bundle equals the declared reservation wage and maximum acceptable commute. This yields one first point of the reservation wage curve. The second step amounts to rotating potential reservation wage curves around the declared reservation job bundle and choosing the reservation curve most consistent with the acceptance strategy of the job search model. We then identify the average slope of the reservation curve by minimizing the sum of squared distances to the reservation curve of accepted bundles that are observed below the reservation curve. We discuss in Section IV.C how classical measurement error and other mechanisms may generate accepted jobs below the reservation wage curve in our data.

Figure VI illustrates the identification strategy. In the logwage-commute plane, we plot the jobs accepted by 10 workers

13. We thank a referee for suggesting this third interpretation. Note that the argument also makes Interpretation 1 more likely than Interpretation 2 bis. 


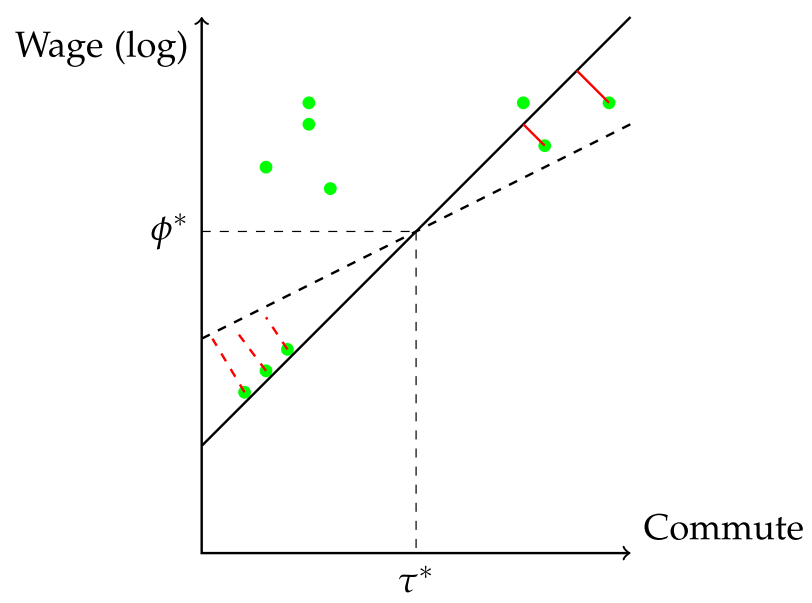

FIGURE VI

Estimation Strategy for the Slope of the Reservation Log-Wage Curve in the Log-Wage-Commute Plane

The figure illustrates the estimation strategy for the slope of the indifference curve in the log-wage-commute plane. Jobs accepted by workers with reported reservation wage $\phi^{*}$ and reservation commute $\tau^{*}$ are drawn as green dots. Under Interpretation 1 , reservation wage curves go through the $\left(\tau^{*}, \phi^{*}\right)$ job. We draw two potential reservation wage curves: the solid and the dashed lines. There are three accepted jobs below the dashed line, while there are only two below the solid line. Moreover, jobs below the dashed line are further away from the dashed line (distances in red and dashed) than jobs below the solid line are distant from the solid line (distances in red and solid). Our estimation strategy chooses the solid line as the reservation wage curve.

with the same reported reservation wage $\phi^{*}$ and reservation commute $\tau^{*}$. Under Interpretation 1 , the reservation wage curve goes through $\left(\tau^{*}, \phi^{*}\right)$. We draw two potential reservation wage curves: the solid and dashed lines. There are three accepted jobs below the dashed line, while there are only two accepted jobs below the solid line. Moreover, jobs below the dashed line are further away from the dashed line than jobs below the solid line are distant from the solid line. In practice, the estimator minimizes the number of accepted jobs that are observed below the reservation curve, weighting more the jobs that are further away from the reservation curve. The estimation strategy picks up the solid line. Note that the identification strategy does not require any assumptions on the exact position of the declared reservation job bundle on the reservation curve: it can be anywhere on the curve. 
We now define the estimator in formal terms. We denote $\left(\tau_{i}, w_{i}\right)$ the pair of commute and wage accepted by individual $i$, $\left(\tau_{i}^{*}, \phi_{i}^{*}\right)$ her declared reservation strategy, and $d_{\alpha, \tau_{i}^{*}, \phi_{i}^{*}}\left(\tau_{i}, w_{i}\right)$ the distance of the job bundle $\left(\tau_{i}, w_{i}\right)$ to the reservation curve of slope $\alpha$ passing through $\left(\tau_{i}^{*}, \phi_{i}^{*}\right)$. We use as a norm the Euclidean distance between the job bundle and its projection on the reservation line. We further denote $\mathcal{B}_{\alpha}$ the set of accepted job bundles below the reservation curve $\left(\mathcal{B}_{\alpha}=\left\{i \mid w_{i}<\phi_{i}^{*}+\alpha\left(\tau_{i}-\tau_{i}^{*}\right)\right\}\right)$. We define the following estimator of the slope $\alpha$ :

$$
\hat{\alpha}=\operatorname{argmin}_{\alpha} \sum_{i \in \mathcal{B}_{\alpha}} p_{i}\left(d_{\alpha, \tau_{i}^{*}, \phi_{i}^{*}}\left(\tau_{i}, w_{i}\right)\right)^{2},
$$

where $p_{i}$ are individual weights that we define to make sure that the distribution of covariates of men matches that of women. We compute $p_{i}$ using inverse probability weighting (Hirano, Imbens, and Ridder 2003). In a first step, we estimate a logit model of being a woman using as covariates the controls $X_{i}$ from the main gender gap regressions. These include worker characteristics (age, education, family status, and work experience), previous job characteristics (past wage, past commute, part-time, labor contract, and occupation) and fixed effects for past industry, commuting zone, and separation year. Using the estimated logit model, we predict the probability to be a female $\hat{p}\left(X_{i}\right)$. In a second step, we define the weights for men as $p_{i}=\frac{\hat{p}\left(X_{i}\right)}{1-\hat{p}\left(X_{i}\right)}$. We run the estimation of $\alpha$ separately for women and men.

Last, we restrict the estimation to non-minimum wage workers. The job acceptance strategy of minimum wage workers is degenerate, as there exists a commute threshold such that minimum wage jobs with commute below this threshold yield more than the reservation utility. We select all job seekers declaring a reservation wage at least $5 \%$ above the minimum wage. This represents $45.8 \%$ of our sample. We verify that our main results from Section III hold in the non-minimum wage workers sample (see Online Appendix Tables D3, D5, and D9). Online Appendix Table D3 shows that the gender gaps in search criteria are similar in this sample, with the gap in reservation wage being one percentage point greater, as expected. We verify the robustness of our results to alternative definitions of the non-minimum wage worker sample. 
TABLE V

Elasticity of Wage With RESPECt to Commute along the Reservation WaGe CuRve

\begin{tabular}{|c|c|c|c|c|c|}
\hline & \multirow[b]{2}{*}{$\begin{array}{l}\text { All } \\
\text { (1) }\end{array}$} & \multicolumn{2}{|c|}{ Without children } & \multicolumn{2}{|c|}{ With children } \\
\hline & & $\begin{array}{l}\text { Single } \\
(2)\end{array}$ & $\begin{array}{c}\text { Married } \\
\text { (3) }\end{array}$ & $\begin{array}{l}\text { Single } \\
\text { (4) }\end{array}$ & $\underset{(5)}{\text { Married }}$ \\
\hline Women & $\begin{array}{l}0.148^{* * * *} \\
(0.0045)\end{array}$ & $\begin{array}{l}0.141^{* * *} \\
(0.0061)\end{array}$ & $\begin{array}{c}0.165^{* * * *} \\
(0.015)\end{array}$ & $\begin{array}{c}0.148^{* * *} \\
(0.013)\end{array}$ & $\begin{array}{c}0.156^{* * * *} \\
(0.010)\end{array}$ \\
\hline Men & $\begin{array}{l}0.121 * * * \\
(0.0046)\end{array}$ & $\begin{array}{l}0.111^{* * * *} \\
(0.0053)\end{array}$ & $\begin{array}{c}0.126^{* * *} \\
(0.014)\end{array}$ & $\begin{array}{c}0.114^{* * * *} \\
(0.013)\end{array}$ & $\begin{array}{c}0.141^{* * * *} \\
(0.010)\end{array}$ \\
\hline Gender gap & $\begin{array}{c}0.027 * * * * \\
(0.0073)\end{array}$ & $\begin{array}{l}0.031^{* * * *} \\
(0.0072)\end{array}$ & $\begin{array}{l}0.039^{*} \\
(0.020)\end{array}$ & $\begin{array}{l}0.034^{*} \\
(0.018)\end{array}$ & $\begin{array}{c}0.015 \\
(0.015)\end{array}$ \\
\hline Obs. & 75,071 & 38,593 & 8,670 & 6,756 & 21,074 \\
\hline
\end{tabular}

Notes. This table presents estimates of the elasticity of the wage with respect to commute along the reservation wage curve. Estimation minimizes the criteria in equation (4). We restrict the sample to job finders and to non-minimum-wage workers who declare a reservation wage at least $5 \%$ above the minimum wage. In column (2), we further restrict the sample to singles without children; in column (3), to married individuals without children; in column (4), to single parents; and in column (5), to married parents. We use inverse probability weighting to balance the covariates of women and men. Bootstrapped standard errors are in parentheses. $* * * p<.01, * p<.1$.

\section{IV.C. Commute Valuation Estimates}

Consistent with Figure V, we consider the log of wages and commutes: we estimate the elasticity along the indifference curve rather than the parameter $\alpha$ directly. Table $\mathrm{V}$ presents our elasticity estimates for women in the first row and for men in the second row. The third row shows the gender gap. In column (1), we pool all non-minimum wage workers. The elasticity of wages with respect to commute distance is 0.15 for women and 0.12 for men. The gender gap is positive and statistically significant at the $1 \%$ level. This confirms that the disutility associated with commute is larger for women than for men. In columns (2) to (5), we split the sample by marriage status and family size. We find that the elasticity increases slightly with household size, but the gender difference remains around the same level, without any statistically significant differences across subgroups. In Online Appendix Table D12, we report the estimates, separately for the Paris region and the rest of France. The gender gap in commute valuation is smaller in Paris than in the rest of France, but the difference is not statistically significant.

1. Interpreting the Magnitude of the Commute Valuation Estimates. Table V shows that gross monthly wages (FTE) must 
be increased by $12 \%$ to compensate men for a doubling in the commuting distance. Given the average commute of 18.6 kilometers and the average monthly wage of $€ 2,018$, an increase of 18.6 kilometers has to be compensated by an increase of $€ 242$ (= $0.12 * 2,018)$ of the monthly wage. The monthly compensating differential for one extra kilometer is about $€ 13$. Assuming that full-time employees commute 22 days a month on average (excluding weekends), the daily compensating differential amounts to 59 cents $\left(=\frac{13}{22}\right)$. How does it compare with the opportunity cost of the time spent commuting? For an increase of one kilometers in the home-work distance, workers spend 3.4 minutes more time commuting per day (assuming an average commuting speed of $35 \mathrm{~km} /$ hour). Workers in our sample have an hourly rate of $€ 13.2$, which translates into 22 cents a minute. Consequently, the compensating differential for men is 0.8 times the hourly wage $\left(=\frac{59}{3.4 \times 22}\right)$. For women, with an elasticity of $14.8 \%$, we obtain a compensating differential of 0.98 times the hourly wage. These estimates of compensating differentials belong to the range of estimates in the literature. Mulalic, Van Ommeren, and Pilegaard (2014) report that estimates of the value of travel time range from $20 \%$ to $100 \%$ of hourly gross wages (Small 1992; Small, Winston, and Yan 2005; Small and Verhoef 2007; Small 2012).

2. Robustness. In Online Appendix Table D13, we show the robustness of the elasticity estimates to other definitions of minimum wage workers and find similar elasticities and gender gaps in commute valuation. However, when we include minimum wage workers in the estimation sample, the gender gap in commute valuation is significantly lower and statistically significant at the $10 \%$ level only. This is expected because minimum wage workers have a degenerate wage offer distribution. Online Appendix Table D14 shows some other robustness tests of the elasticity estimates. Column (1) does not use inverse probability weighting to balance the male and female sample on covariates. Column (2) restricts the sample to workers who declare their maximum commute in kilometers. Column (3) excludes workers with a large deviation between the accepted commute and the reservation commute, for whom nonlinearities are a potential concern. In column (4), we adopt another minimization criteria: the number of accepted bundles below the reservation wage curve (without weighting them by their distance to the curve). Results are robust to these changes of specification. In column (5), we restrict the estimation sample to 
individuals who worked full-time in their previous job. The gender difference in elasticity is smaller when we hold constant the past hours worked, but still significant. This suggests that gender differences in commute valuation come on top of potential gender differences in hours flexibility.

In Online Appendix A, we adopt alternative interpretations of the reported reservation job $\left(\phi^{*}, \tau^{*}\right)$ (Interpretation 2 and 2 bis). We find again that women have a significantly higher willingness to pay for a shorter commute than men: $23.8 \%$ higher under Interpretation 2 and $15.1 \%$ higher under Interpretation 2 bis (see Online Appendix Tables A1 and A2).

\section{Accepted Job Bundles below the Reservation Wage Curve?} Several mechanisms may explain why we observe accepted job bundles below the reservation wage curve. First, it could be due to measurement error in reservation or accepted job attributes. In Online Appendix Table D14, column (6), we add white noise to the data and show that our results are robust to measurement error, with some attenuation bias. This suggests that our main estimate is a lower bound of gender gaps in WTP for a shorter commute. Nonstationarity in job search behaviors is a second possible mechanism, as we pin down the reservation wage curve using reservation job attributes declared at the beginning of the spell. We find that the share of workers who accept jobs that are above their reservation wage curve is 3 percentage points lower for workers who have one more year of unemployment (from an initial share of $83 \%$ ). This makes duration dependence a marginal contributor to points below the reservation wage curve. The existence of other job amenities is a third possible mechanism. Assuming that workers declare their reservation job attributes conditional on other amenities being at their average, they may accept jobs below the reservation wage curve when amenities are high. As long as the mechanism generating accepted jobs below the reservation wage curve is independent of wage and commute offers, the WTP estimator in equation (4) is still valid, as our simulations related to measurement error suggest. In Section VI.B, we propose an alternative estimation of the gender gap in commute valuation, based on an empirical model of application choice. This approach is robust to unobserved nonwage job amenities that are potentially correlated with wages and commute and provides similar estimates of the gender gap in WTP. 
In this section, we have showed that women have a $22 \%$ higher willingness to pay for a shorter commute $\left(\frac{0.027}{0.121}=0.223\right.$, see Table V column (1)). This result comes from a new (to the best of our knowledge) identification strategy that leverages unique data on job search criteria. The identification strategy mostly relies on the form of the utility function when employed and on the reservation strategy embedded in standard job search models. Specifically, the commute valuation parameter is separately identified from the other model parameters, as long as the job offer distributions are not degenerate. This is worth noting, as an alternative hypothesis supporting the gender gaps documented in Section III could be that men and women do not draw job offers from the same distributions when unemployed (even if they had similar jobs before unemployment). Even in this case, our result on gender differences in willingness to pay for a shorter commute still holds. Next we draw the implications of the gender differences in commute valuation for the gender wage gap.

\section{ImPlications For the Gender Wage GaP}

Because women must be compensated more than men to accept far-away jobs, they are more likely to work close to home in jobs that pay relatively less. To what extent do gender differences in commute valuation contribute to the gender wage gap? To quantify this, we first calibrate the job search model above, using the previous estimate of the WTP for a shorter commute. Second, we perform counterfactual simulations where we shock this commute valuation parameter.

\section{V.A. Calibration of the Job Search Model}

We calibrate the model, restricting our sample to nonminimum wage workers on which we have estimated the WTP for a shorter commute, $\alpha$. We proceed as follows.

First, we calibrate $r$ such that the yearly discount rate is $12 \%$ (following Van Den Berg 1990) and the match destruction rate $q$ is equal to the inverse of the length of jobs in the subsample of interest (for the median job seeker, a job spell lasts 12 months). Second, we observe in the data the pair $\left(\tau^{*}, \phi^{*}\right)$, which is a point on the reservation curve, and the previous section yields an estimate of the commute valuation $\alpha$. We can build the full reservation curve; in particular we deduce $\phi(0)=\phi^{*}-\alpha \tau^{*}$. 
Knowing the reservation curve, we use the empirical measures of the expectation and variance of the residualized log of the reemployment wage $w^{n}$ and commute $\tau^{n}$ to pin down the job offer distributions (see equations (2) and (3) for expectations). We residualize the reemployment wage and commute with the same covariates as in the main gender gap regressions. This aims at focusing on wage and commute variations arising from random search. We assume that log-wage and commute are drawn independently from the distributions $F$ and $G$, respectively. The distribution of the log-wage offers $F$ is a gamma distribution and we estimate its shape $k_{F}$ and scale $\theta_{F}$. For the distribution of commute offer $G$, we assume the following probability density function, defined over the support 0 to 100 kilometers:

$$
g(\tau)=\gamma\left(\tau ; k_{G}, \theta_{G}\right)+\tau .
$$

The distribution $G$ is a mixture of a gamma distribution with shape $k_{G}$ and scale $\theta_{G}$ and of a linear distribution. The functional form of $G$ is consistent with the distribution of distances between job seekers' residence and workplaces of vacancies posted on the French PES website (see Online Appendix Figure C8). Intuitively, the linear term accounts for the increase in further-away jobs when the disk of radius $\tau$ centered on the worker's residence expands over a two-dimensional uniform density of jobs. For $F$ and $G$, there are four moments to pin down four parameters by GMM estimation.

We use the observed job-finding rate to determine the job offer arrival rate $\lambda$. Namely, we use the fact that the job-finding rate should be equal to:

$$
\lambda \int_{0}^{\infty} \int_{\phi(0)+\alpha \tau}^{\infty} d F(w) d G(\tau)
$$

The flow unemployment utility $b$ is finally obtained as the solution of equation (1). The quantities involved in the calibration and the resulting structural parameters are summarized in Online Appendix Table D15 for the sample of women.

\section{V.B. Decomposition of the Gender Wage Gap}

The counterfactuals are obtained as follows. Keeping all other structural parameters unchanged $(r, q, \lambda, F(), G()$, and $b)$, we replace the commute valuation parameters $\alpha$ we have estimated for 
TABLE VI

Contribution of Gender Differences in Commute Valuation to Gender Gaps IN WAGE AND COMMUTE

\begin{tabular}{lccc}
\hline \hline & \multicolumn{2}{c}{$\begin{array}{c}\text { Contribution to the } \\
\text { observed gender gaps in }\end{array}$} & $\begin{array}{c}\text { Commute } \\
\text { valuation }\end{array}$ \\
\cline { 2 - 3 } & $\begin{array}{c}\text { Wage } \\
(1)\end{array}$ & $\begin{array}{c}\text { Commute } \\
(2)\end{array}$ & $\begin{array}{c}\text { shock } \\
(3)\end{array}$ \\
\hline With all controls & $13.8 \%$ & $140.6 \%$ & $-18.2 \%$ \\
Removing previous job controls & $10 \%$ & $93.4 \%$ & $-18.9 \%$ \\
Broken down by family status, with all controls & & \\
Single, no kids & $19.9 \%$ & $215.2 \%$ & $-18.2 \%$ \\
Married, no kids & $13.1 \%$ & $117.6 \%$ & $-18.2 \%$ \\
Single, with kids & $10 \%$ & $121.6 \%$ & $-18.2 \%$ \\
Married, with kids & $14 \%$ & $102 \%$ & $-18.2 \%$ \\
\hline \hline
\end{tabular}

Notes. The table reports the share of the empirical gender gaps in wage and commute of the next job explained by gender differences in commute valuation. The decomposition is based on the job search model in Section IV. We shock the commute valuation parameter of women by the average difference in $\alpha$ in column (1) of Table V, except in the second row. We report the commute valuation shock in column (3). The decomposition exercise controls for all variables in our main gender gap regressions, except in the second row, where we remove the controls related to the previous job and work history. We simulate the job search model to predict the gender gap in wage and commute of the next job; we report in the first two columns how much this explains of the observed reemployment wage and commute gaps. In the lower panel, we break down the decomposition exercise by marital and parental status.

women by those estimated for men. In practice, we reduce $\alpha$ by $18.2 \%$, the average difference between men and women as estimated in the previous section $\left(\frac{0.027}{0.148}=0.182\right.$, see Table V, column (1)).

Reducing $\alpha$ in the job search model increases accepted wages and commute through two channels, related to the rotation and the shift of the reservation curve, respectively. The rotation of the reservation wage curve-holding reservation utility constantimplies that the fraction of jobs accepted further away from home increases. Because further-away jobs pay more, the rotation implies both an increase in wage and commute. In addition, lowering $\alpha$ increases the utility when employed and thus the reservation utility. This induces an upward shift in the reservation wage curve, which further increases accepted wages.

1. Results. The results of this simulation are shown in Table VI. The last column shows the magnitude of the shock in commute valuation. The first column reports the share of the gender gap in the residualized FTE wage of the next job that is 
explained by the reduction in $\alpha .{ }^{14}$ The second column does the same exercise for commute. In the upper panel, we perform the decomposition for women, whatever their family status. We find that gender differences in commute valuation (i.e., in $\alpha$ as estimated in Section IV) explain $13.8 \%$ of the residualized FTE wage gap, that is, a $0.5 \mathrm{log}$ point hourly wage deficit for women. These differences in $\alpha$ explain more than $100 \%$ of the differences in commute. Note that fully explaining the gender commute gap is not a mechanical result, and it did not need to be the case. Men and women are likely to differ along other dimensions than $\alpha$ that we hold constant in the simulations, and these differences in other dimensions may trigger differences in observed commute as well. In Online Appendix Table D17, we perform another simulation exercise where the reduction in commute valuation is such that the explained share of the gender gap in commute of the next job is exactly equal to $100 \%$. The resulting explained shares of observed wage gaps are around $10 \%$, a bit lower but fairly similar to those in Table VI.

As the previous jobs of the unemployed are likely to depend on their commute valuation, we also perform the decomposition exercise removing past wages and past commutes from the list of controls. This leads to three main changes. First, we calibrate the model with higher residualized variances of accepted wages and commutes. Second, the gender gap in commute valuation slightly increases from $18.2 \%$ to $18.9 \%$ when the inverseprobability weights of the WTP estimator do not include the past job attributes (see the third column in Table VI). Third, the observed gender gaps in accepted wages and commutes that we are trying to explain (i.e., the denominator for columns (1) and (2)) are larger. ${ }^{15}$ Although the second change increases the simulated gender gaps in accepted jobs, the third change tends to decrease the fraction explained. All in all, we obtain that gender gaps in commute valuation explain $10 \%$ of the observed gender wage gap, that is, $0.8 \mathrm{log}$ points of the FTE wage deficit of women, and $93 \%$ of the observed commute gap (see second row in Table VI). This is broadly consistent with the previous results.

14. The denominator of this ratio comes from the estimation of gender gaps in reemployment outcomes in the non-minimum wage sample, see Online Appendix Table D5 and D9.

15. On the non-minimum wage workers sample, the gender gaps in accepted wage and accepted commute amount to $7.7 \%$ and $25.3 \%$, respectively, when we do not control for past jobs. 
2. Heterogeneity by Family Status. In the lower panel of Table VI, we perform the decomposition exercise broken down by family status. The model is calibrated for each subgroup separately. Online Appendix Table D16 provides the values of estimated/calibrated parameters for all subgroups. We conclude from Table V that there is no statistically significant heterogeneity in gender gaps in commute valuation: we choose here to shock all subgroups using the same average gender gap in WTP. We find that gender gaps in commute valuation explain between $10 \%$ and $20 \%$ of the wage gap, depending on the subgroup but with no clear pattern as a function of family size.

\section{Robustness to Alternative Interpretations of the Reported} Search Criteria. Online Appendix A shows a decomposition exercise under alternative interpretations of the reported reservation job $\left(\phi^{*}, \tau^{*}\right)$ (Interpretations 2 and 2 bis). In Online Appendix Table A3, the share of gender wage gap explained by gender differences in commute valuation is between $9 \%$ and $15 \%$. Overall, our decomposition exercise delivers robust results, suggesting that a meaningful share of the gender wage gap can be explained by gender differences in commute valuation.

4. Discussion. In the simulations above, we account for the endogenous response of the workers' reservation utility. This is a partial equilibrium approach, to the extent that we do not account for employers' response. In a model with endogenous wage offer distributions, reducing the commute valuation parameter as we do above would push further toward higher wages because it increases workers' reservation utility and employers would respond by offering higher wages. Such general equilibrium effects à la Black (1995) would strengthen the contribution of the gender gap in commute valuation to the gender wage gap. Consequently, we see our main results above as lower bounds.

Although our empirical results in Section III include a rich set of covariates to control for differences in employment opportunities, one may still be concerned that a gender differential in the distribution of offered wages may explain the gender gap in observed commutes. We quantify this alternative explanation using our calibrated job search model. We compute the elasticities of realized wages and commutes with respect to the expectation of wage offers (via the location parameter of the gamma distribution). We find that a shock of $12 \%$ on the expectation of wage offers 
is necessary to account for the $4 \%$ gender gap in realized wages, and that this shock can only explain a third of the $12 \%$ gender gap in realized commutes. Although we cannot rule out that women and men have different wage offer distributions, even conditional on the covariates we introduce, the exercise shows that differentials in the wage distributions alone are unlikely to generate the observed differentials in commutes.

Overall, the decomposition results rank gender differences in WTP for a shorter commute as an important driver of the gender wage gap. Mas and Pallais (2017) find that "with a 20 percent compensating differential for both work at home and working a fixed schedule instead of an irregular one, the differences by gender in the prevalence of these arrangements would only lead to a 1.7 percent raw gender wage gap or a 2.0 percent gap with controls." Wiswall and Zafar (2017) find that gender differences in students' preferences for future earnings growth, probability of dismissal, and working-hours flexibility, account for one quarter of the gender earnings gap. Bertrand, Goldin, and Katz (2010) find that for MBA graduates, $30 \%$ of the gender wage gap is accounted for by gender differences in hours of work a week.

\section{Further Insights From ApPlication Data}

In this section, we present further insights using application data. We leverage a rich administrative data set that records applications of job seekers to vacancies posted at the French PES and their hiring outcomes. ${ }^{16}$ We first estimate a conditional logit model of application choices with job ad fixed effects, and we show that the commute distance between the vacancy workplace and the applicants' residence has a larger influence (by around 20\%) for women than for men. This is in line with the gender gap in commute valuation estimated in Section IV. This shows the robustness of our main results to (i) relying on actual behaviors only (without using reported search criteria) and (ii) the concern of unobserved correlated amenities. Second, we study labor demand. We find that firms do not specifically lower their hiring of women compared with men when applicants live further away.

16. See Behaghel, Crépon, and Le Barbanchon (2015) for previous analysis of application data at the French PES. 


\section{VI.A. Application Data}

French employers typically post vacancies on the PES website and advertise them through local agencies. In 2010, vacancies posted at PES represented $60 \%$ of all hires in France (authors' calculation). Workers registered as job seekers may apply through the PES website or local agencies. This generates entries into an application data set at the vacancy $\times$ worker identifier level. We can thus analyze workers' application choices as a function of the attributes of the vacancies. Furthermore, caseworkers record the application outcome: hired or not. This allows us to analyze the hiring outcome in the pool of applicants, and to get closer to labor demand. ${ }^{17}$ We observe more than 3 million applications for the sample of workers described in Section II.A. ${ }^{18}$ We restrict the sample to applications from 2010 to 2012, because we do not observe the vacancy workplace before 2010 .

Table VII reports summary statistics for applications, vacancies, and applicants. Panel A reports statistics at the application level. Around 5\% of applications lead to hiring. The average commute between the vacancy workplace and the applicant's home is 19 kilometers, very similar to the average commute reported in Table I. The posted wage is on average $€ 1,539$. This is $25 \%$ lower than the average previous wage of the main sample of job seekers in Table I, and close to the legal minimum wage of around $€ 1,400$ in 2010-2012. Indeed, $44 \%$ of vacancies report the minimum wage as their posted wage. All vacancies report an occupation and a required qualification (low- or high-skilled blue collar work, low- or high-skilled employee, or manager). For almost half of the applications, the applicant meets the required qualification. Similarly, in almost half of the cases, the applicant selects a job in their preferred occupation.

Almost one applicant out of four is hired from a vacancy posted by the PES (see Table VII, Panel C). This builds confidence in the relevance of PES postings and applications for

17. In general, hiring is an equilibrium outcome resulting from the interaction of labor supply and labor demand. In our setting, we analyze hirings of workers applying for detailed job ads (including wages). We thus argue that if employers offer the job to an applicant, it is likely that she accepts the offer. Consequently, hirings in our setting are rather informative of employers' choice among applicants.

18. The sample of applicants is larger than the main sample described in Section II. To maximize statistical power, we also include workers who do not claim unemployment benefits. 
TABLE VII

Summary Statistics of ApPlication Dataset

\begin{tabular}{|c|c|c|c|}
\hline & $\begin{array}{c}\text { Mean } \\
\text { (1) }\end{array}$ & $\begin{array}{l}\text { Std. dev. } \\
\text { (2) }\end{array}$ & $\begin{array}{l}\text { Obs. } \\
(3)\end{array}$ \\
\hline Panel A: Application level & & & $3,103,522$ \\
\hline Hiring & 0.052 & 0.221 & \\
\hline Female applicant & 0.489 & 0.5 & \\
\hline Posted wages (gross, monthly, euros) & 1,539 & 336 & $2,923,929^{c}$ \\
\hline Commute $(\mathrm{km})$ & 18.8 & 21.3 & \\
\hline Same three-digit occupation ${ }^{a}$ & 0.481 & 0.5 & \\
\hline \multicolumn{4}{|l|}{ Applicant has: } \\
\hline Required qualification ${ }^{\mathrm{b}}$ & 0.414 & 0.49 & \\
\hline Required education & 0.448 & 0.497 & $1,413,928^{c}$ \\
\hline Required experience & 0.855 & 0.352 & $2,132,700^{c}$ \\
\hline Panel B: Vacancy level & & & $1,802,276$ \\
\hline Hiring $^{d}$ & 0.948 & 0.22 & \\
\hline No. applicants per vacancy ${ }^{\mathrm{d}}$ & 20.7 & 16.5 & \\
\hline Full-time position & 0.73 & 0.444 & \\
\hline Open-ended contract & 0.39 & 0.488 & \\
\hline Requires education level & 0.473 & 0.499 & \\
\hline Required education level (years) & 12.09 & 2.60 & \\
\hline Requires experience & 0.699 & 0.459 & \\
\hline Required experience level (months) & 6.89 & 12.88 & \\
\hline Panel C: Applicant level & & & 488,578 \\
\hline Hiring & 0.238 & 0.426 & \\
\hline No. applications per job seeker & 6.35 & 8.93 & \\
\hline Women & 0.501 & 0.5 & \\
\hline Education (years) & 11.41 & 3.35 & \\
\hline Experience (months) & 63.6 & 77.9 & \\
\hline Foreigner & 0.119 & 0.324 & \\
\hline
\end{tabular}

Notes. The table reports summary statistics on workers' applications for job ads posted on the French PES online job board from 2010 to 2012. In Panel A, we report statistics at the application level. In Panel B, we collapse the data set at the vacancy level; in Panel C, we collapse the data set at the applicant/worker level.

aThe vacancy occupation is the same as the applicant's preferred occupation (three-digit level).

${ }^{b}$ Low- or high-skilled blue collar workers, low- or high-skilled employees, or managers.

cNot all vacancies post wages or explicitly require education/experience levels. Consequently we report separately the number of observations for these dimensions.

d As we observe $\frac{1}{12}$ of job seekers, we multiply the sample means by 12 to obtain the population means.

labor market clearing. Conditional on applying at least once, applicants apply on average for six vacancies. From the employer's side of the market (see Panel B), 94\% of vacancies are filled by an applicant applying through the PES, and job ads receive 21 applications on average. Overall, firms and applicants have a high probability of finding a match through the PES marketplace conditional on posting and applying respectively. However, there is 
still selection into PES posting for firms and into PES applying for workers. This is certainly an issue when measuring the number of applicants for a given vacancy or the overall search intensity of a given job seeker. For example, some applicants directly apply through company websites. It is unclear though why this selection should be differential by gender. We argue that this selection margin leads to second-order bias when documenting gender differences in the influence of job attributes on application choices, or when analyzing the gender hiring gap as a function of applicants' characteristics.

\section{VI.B. Gender Differences in Commute Valuation in an Application Model}

In this section, we analyze the application data from the job seeker's perspective. We fit an econometric model of application choices and study how commute affects the application decision differentially for women and men. One recurrent issue when identifying the influence of one attribute in choice models is that other unobserved amenities may be correlated with the job attribute of interest. This may confound the parameter of interest. However, as commute is a match-specific attribute, correlated amenities are less problematic because we can control for unobserved job attributes common to all workers. Holding constant these job attributes, we test whether workers who live closer to the workplace have a higher propensity to apply for the job.

We define the choice set of workers as follows. For each job seeker who registers in a given quarter, we assign her the vacancies that are (i) in her commuting zone of residence, (ii) in the same three-digit occupation as the one she is looking for, and (iii) posted in the quarter following her registration. Our data give us the vacancies to which the individual worker applies within her choice set. We restrict the sample to job seekers who make at least one such application. We estimate a conditional logit model for the probability of applying for these vacancies controlling for job ad fixed effects. In a structural choice model, the application decision depends on posted wages, but the wage coefficient cannot be identified when job ad fixed effects are included. On the contrary, the coefficient on commuting distance is still identified in this model as commuting varies across workers paired with the same vacancy. We further interact the job ad fixed effects with gender to account for unobserved job characteristics that men and women may value differentially. The probability that worker $i$ applies for 
TABLE VIII

Probability of Applying for a Job as a Function of Its Distance to Home

\begin{tabular}{lccc}
\hline \hline & \multicolumn{3}{c}{ Applied } \\
\cline { 2 - 4 } & $(1)$ & $(2)$ & $(3)$ \\
\hline Log commute & $-0.562^{* * *}$ & $-0.570^{* * * *}$ & $-0.574^{* * *}$ \\
& $(0.00528)$ & $(0.00712)$ & $(0.00711)$ \\
Female $\times$ log commute & $-0.0767^{* * *}$ & $-0.129^{* * *}$ & $-0.129^{* * *}$ \\
& $(0.00746)$ & $(0.0113)$ & $(0.0113)$ \\
Job fixed effects $\times$ gender & $\mathrm{X}$ & $\mathrm{X}$ & $\mathrm{X}$ \\
Worker controls & & & $\mathrm{X}$ \\
Sample & & $>\min \mathrm{W}$ & $>\min \mathrm{W}$ \\
& & $3,390,516$ & $3,390,516$ \\
Observations & $6,315,615$ & 48,317 & 48,317 \\
No. of job seekers & 105,130 & 179,013 & 179,013 \\
No. of job ads & 197,099 & \\
\hline \hline
\end{tabular}

Notes. Sample: Potential matches between job seekers and vacancy/job ads posted at the PES. In columns (2) and (3), the sample is restricted to non-minimum wage workers. Compared with the sample in Table VII, we drop markets (defined by $\mathrm{CZ} \times$ occupation $\times$ quarter) with fewer than 30 applications. We further keep potential matches of job seekers in their relevant market and during their first quarter of unemployment.

We estimate a conditional logit model of application choices with job ad fixed effects interacted with gender. In the table, we report the estimates of the coefficients of the log commute and its interaction with a female dummy. Commute is the distance between the job seeker's residence and the vacancy's workplace. Worker controls include dummies for age, education, and experience, as well as being foreign born. Robust standard errors are in parentheses. $* * * p<.01$.

vacancy $j$ has the following specification:

$$
\begin{aligned}
& \mathcal{P}\left(A_{i j}=1 \mid \text { Commut }_{i j}, a_{j}, \text { Female }_{i}, X_{i}\right)= \\
& \frac{\exp \left(\beta \log \text { Commute }_{i j}+\delta \text { Female }_{i} \times \log \text { Commute }_{i j}+a_{j} \times \text { Female }_{i}+\beta X_{i}\right)}{1+\exp \left(\beta \log \text { Commute }_{i j}+\delta \text { female }_{i} \times \log \text { Commute }_{i j}+a_{j} \times \text { Female }_{i}+\beta X_{i}\right)},
\end{aligned}
$$

where $A_{i j}$ indicates whether worker $i$ applies for vacancy $j, a_{j} \times$ Female $_{i}$ is a vacancy fixed effect interacted with gender, and $X_{i}$ are workers' covariates (age, education, experience, and nationality). The main coefficient of interest is $\delta$, which is the differential effect of commute on application decision across gender.

In Table VIII, we report the estimates of the coefficients $\beta$ and $\delta$ of the log commute and its interaction with a female dummy from the conditional logit model. We find that a longer distance between the job seeker's residence and the vacancy workplace reduces significantly the probability of applying and even more so for women. This is robust to restricting the sample to nonminimum wage workers (column (2)) and to introducing workers' controls (column (3)). We do not interpret the level of each estimate separately (as the wage coefficient is not identified). However the 
ratio between the two coefficient estimates is meaningful. We find that women have a commute valuation that is $14 \%$ to $23 \%$ larger than men $\left(=\frac{0.08}{0.56}\right.$ and $\left.=\frac{0.13}{0.57}\right)$. This is in line with our main results in Section IV. When we introduce workers' covariates in column (3), this barely affects the estimates.

In Online Appendix B, we perform another empirical test that women have a higher WTP for a shorter commute than men. Among vacancies to which workers apply, we regress the log posted wages on the log commute and on the log commute interacted with a female dummy. Controlling for workers' fixed effects, we find that the elasticity of posted wages with respect to commute is significantly stronger for women than for men. The link between this estimated elasticity and the WTP parameter is not as direct as above, because the regression is on applied vacancies only. All observations are above the reservation wage curve, which will yield elasticity estimates smaller than the WTP parameter. We view this exercise as a qualitative robustness test, which allows us to easily control for workers' unobserved heterogeneity.

\section{VI.C. What about Labor Demand?}

We have shown in Section III that, when newly unemployed, women and men set different search criteria: women search for closer and not-so-well-paid jobs compared with men. Our main interpretation is that these differences are due to differences in the utility function of men and women, and how they weigh commuting distances versus wages. Another interpretation may be that gender differences in search criteria reflect differences in the labor demand for male and female workers, in which case women would report seeking a job closer to home than men because they expect fewer job offers from distant workplaces. In other words, they would be internalizing a lower labor demand from far-away employers. Below we test this alternative explanation and find that differences in labor demand are unlikely to explain gender gaps in search strategy.

Figure VII plots the hiring rate of applicants as a function of the distance between the worker's home and the vacancy's location, within the pool of applicants to the same vacancy. On top of vacancy fixed effects, we control for the applicants' age, education level, and experience. The reduction in hiring rate with distance looks similar for men and women.

In Online Appendix B, we document this finding in a regression framework. The gender difference in the marginal effect of a 


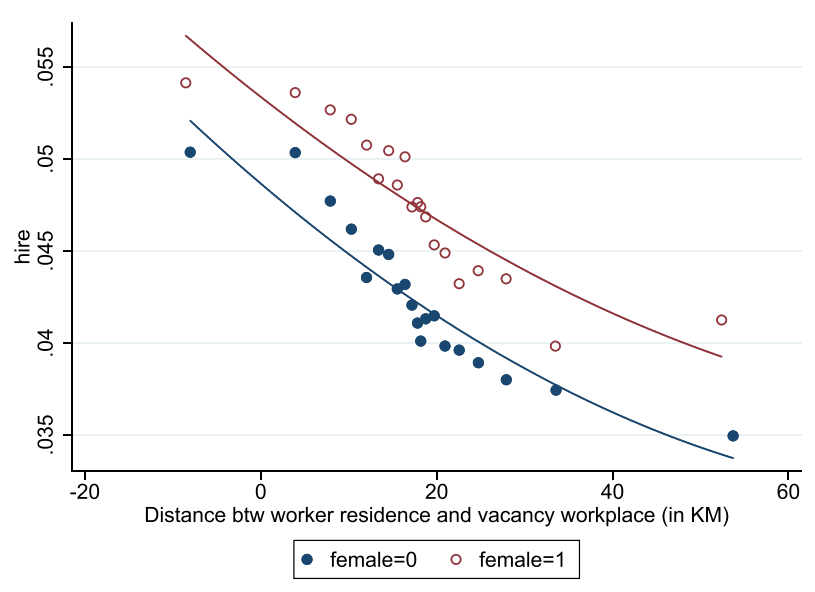

FIGURE VII

Applicants' Hiring Rate as a Function of Their Commute to the Vacancy's Workplace, by Gender

The figure presents a binned scatterplot of the hiring rate versus the distance between the worker's residence and the vacancy's workplace, for men (blue dots) and for women (red open circles). The sample consists in applications of workers for jobs posted on the PES website from 2010 to 2012. The sample is restricted to job ads receiving applications from both women and men. The hiring rate and the commute distance are residualized using vacancy/ad fixed effects and worker characteristics (age, education, and experience).

10 kilometer commute increase on the hiring rate is as small as 0.08 percentage points, and not statistically significant at the $5 \%$ level in our preferred specification. Overall, we find that firms do not specifically lower their hiring of women compared with men when applicants live further away.

\section{CONCLUSION}

Our article documents gender differences in job seekers' search criteria, controlling finely for the characteristics of their previous job. Even single women without children have a $2 \%$ lower reservation wage and are willing to accept at most a commute $8 \%$ shorter than comparable men. These figures increase to $6 \%$ and $24 \%$, respectively, for married women with children. The gaps also grow with age, following a similar pattern to that observed for wages and commutes in the overall working population.

We then use the joint distribution of reservation wages and commutes together with reemployment outcomes to estimate the 
slope of reservation wage curves. We find that the value of commute time amounts to $80 \%$ of the gross hourly wage for men and $98 \%$ for women, a difference that is statistically significant. We build a job search model where commuting matters and show that our estimated gender differences in commute valuation can account for around 14\% of the residualized gender gap in hourly wage on reemployment. We show that our estimated gender gap in commute valuation is robust to using a different approach, based on applications data. We also provide evidence that the gender differences in search criteria are not driven by labor demand.

By highlighting the importance of gender differences in willingness to commute and linking it to the gender wage gap, we shed light on possible ways to further reduce gender wage inequality. Technological progress that lowers the firms' cost of remote work has the potential to further decrease the gender wage gap (Bloom et al. 2014). More generally, public policies on urban planning and transportation have the potential to change commuting patterns differently for men and women and may have differential effects on their relative wages (e.g., Redding and Turner 2015; Bütikofer, Løken, and Willén 2019). On a related note, offering financial subsidies to job seekers who apply for or accept more distant jobs may affect men and women differently, and thus the gender wage gap (Glover and Roulet 2018).

BOCCONI UNIVERSITY

UNIVERSITY OF WARWICK

INSEAD

\section{SUPPLEMENTARY MATERIAL}

An Online Appendix for this article can be found at The Quarterly Journal of Economics online (qje.oxfordjournal.org).

\section{Data Availability}

Code replicating the tables and figures in this article can be found in Le Barbanchon, Roulet, and Rathelot (2020), in the Harvard Dataverse, doi: 10.7910/DVN/16QOSR.

\section{REFERENCES}

Adda, Jérôme, Christian Dustmann, and Katrien Stevens, "The Career Costs of Children," Journal of Political Economy, 125 (2017), 293-337. 
Altonji, Joseph G., and Christina H. Paxson, "Labor Supply, Hours Constraints, and Job Mobility," Journal of Human Resources, 27 (1992), 256-278.

Angelov, Nikolay, Per Johansson, and Erica Lindahl, "Parenthood and the Gender Gap in Pay," Journal of Labor Economics, 34 (2016), 545-579.

Behaghel, Luc, Bruno Crépon, and Thomas Le Barbanchon, "Unintended Effects of Anonymous Resumes," American Economic Journal: Applied Economics, 7 (2015), 1-27.

Bertrand, Marianne, "New Perspectives on Gender," in Handbook of Labor Economics volume 4, O. Ashenfelter and D. Card, eds. (Amsterdam: Elsevier, 2011), 1543-1590.

Bertrand, Marianne, Claudia Goldin, and Lawrence F. Katz, "Dynamics of the Gender Gap for Young Professionals in the Financial and Corporate Sectors," American Economic Journal: Applied Economics, 2 (2010), 228-255.

Black, Dan A., "Discrimination in an Equilibrium Search Model," Journal of Labor Economics, 13 (1995), 309-334.

Black, Dan A., Natalia Kolesnikova, and Lowell J. Taylor, "Why Do So Few Women Work in New York (and So Many in Minneapolis)? Labor Supply of Married Women across US Cities," Journal of Urban Economics, 79 (2014), 59-71.

Blau, Francine D., and Lawrence M. Kahn, "The Gender Wage Gap: Extent, Trends, and Explanations," Journal of Economic Literature, 55 (2017), 789865.

Bloom, Nicholas, James Liang, John Roberts, and Zhichun Jenny Ying, "Does Working from Home Work? Evidence from a Chinese Experiment," Quarterly Journal of Economics, 130 (2014), 165-218.

Bolotnyy, Valentin, and Natalia Emanuel, "Why Do Women Earn Less Than Men? Evidence from Bus and Train Operators," Mimeo, Harvard University, 2019.

Bonhomme, Stephane, and Gregory Jolivet, "The Pervasive Absence of Compensating Differentials," Journal of Applied Econometrics, 24 (2009), 763-795.

Brown, Charles, "Equalizing Differences in the Labor Market," Quarterly Journal of Economics, 94 (1980), 113-134.

Brown, Sarah, Jennifer Roberts, and Karl Taylor, "The Gender Reservation Wage Gap: Evidence from British Panel Data," Economics Letters, 113 (2011), 88-91.

Bütikofer, Aline, Løken Katrin, and Alexander Willén, "Building Bridges and Widening Gaps: Efficiency Gains and Equity Concerns of Labor Market Expansions," NHH Working Paper No. 2017-10, 2019.

Caldwell, Sydnee, and Oren Danieli, "Outside Options in the Labor Market," Mimeo, Harvard University, 2019.

Caliendo, Marco, Wang-Sheng Lee, and Robert Mahlstedt, "The Gender Wage Gap and the Role of Reservation Wages: New Evidence for Unemployed Workers," Journal of Economic Behavior \& Organization, 136 (2017), 161-173.

Clark, Ben, Kiron Chatterjee, Adam Martin, and Adrian Davis, "How Commuting Affects Subjective Wellbeing," Transportation (2019), doi: 10.1007/s11116-01909983-9.

Crane, Randall, "Is There a Quiet Revolution in Women's Travel? Revisiting the Gender Gap in Commuting," Journal of the American Planning Association, 73 (2007), 298-316.

Feldstein, Martin, and James Poterba, "Unemployment Insurance and Reservation Wages," Journal of Public Economics, 23 (1984), 141-167.

Filer, Randall K., "Male-Female Wage Differences: The Importance of Compensating Differentials," Industrial and Labor Relations Review, 38 (1985), $426-437$.

Flory, Jeffrey A., Andreas Leibbrandt, and John A. List, "Do Competitive Workplaces Deter Female Workers? A Large-Scale Natural Field Experiment on Job Entry Decisions," Review of Economic Studies, 82 (2014), $122-155$.

Fluchtmann, Jonas, Anita M. Glenny, Nikolaj Harmon, and Jonas Maibom, "The Gender Application Gap: Do Men and Women Apply for the Same Jobs?" Mimeo, University of Copenhagen, 2020. 
Glover, Dylan, and Alexandra Roulet, "Geographic Mobility and the Gender Wage Gap: Evidence from a Randomized Experiment," INSEAD Working Paper, 2018.

Goldin, Claudia, "A Grand Gender Convergence: Its Last Chapter," American Economic Review, 104 (2014), 1091-1119.

Goldin, Claudia, and Lawrence F. Katz, "A Most Egalitarian Profession: Pharmacy and the Evolution of a Family-Friendly Occupation," Journal of Labor Economics, 34 (2016), 705-746.

Guglielminetti, Elisa, Rafael Lalive, Philipp Ruh, and Etienne Wasmer, "Spatial Search Strategies of Job Seekers and the Role of Unemployment Insurance," Sciences Po Working Paper, 2015.

Hirano, Keisuke, Guido W. Imbens, and Geert Ridder, "Efficient Estimation of Average Treatment Effects Using the Estimated Propensity Score," Econometrica, 71 (2003), 1161-1189.

Hwang, Hae-Shin, W. Reed, and Carlton Hubbard, "Compensating Wage Differentials and Unobserved Productivity," Journal of Political Economy, 100 (1992), 835-858.

Kleven, Henrik, Camille Landais, Johanna Posch, Andreas Steinhauer, and Josef Zweimüller, "Child Penalties across Countries: Evidence and Explanations," AEA Papers and Proceedings, 109 (2019), 122-126.

Kleven, Henrik, Camille Landais, and Jakob Egholt Søgaard, "Children and Gender Inequality: Evidence from Denmark," American Economic Journal: Applied Economics, 11 (2019), 181-209.

Krueger, Alan B., and Andreas I. Mueller, "A Contribution to the Empirics of Reservation Wages," American Economic Journal: Economic Policy, 8 (2016), 142-179.

Le Barbanchon, Thomas, Roland Rathelot, and Alexandra Roulet, "Unemployment Insurance and Reservation Wages: Evidence from Administrative Data," Journal of Public Economics, 171 (2019), 1-17.

Le Barbanchon, Thomas, Alexandra Roulet, and Roland Rathelot, "Replication Data for: 'Gender Differences in Job Search: Trading off Commute against Wage'," (2020), Harvard Dataverse, doi: 10.7910/DVN/16QOSR.

MacDonald, Heather I., "Women's Employment and Commuting: Explaining the Links," Journal of Planning Literature, 13 (1999), 267-283.

Maestas, Nicole, Kathleen J. Mullen, David Powell, Till von Wachter, and Jeffrey B. Wenger, "The Value of Working Conditions in the United States and Implications for the Structure of Wages," NBER Working Paper no. 25204, 2018.

Manning, Alan, "The Real Thin Theory: Monopsony in Modern Labour Markets," Labour Economics, 10 (2003), 105-131.

Mas, Alexandre, and Amanda Pallais, "Valuing Alternative Work Arrangements," American Economic Review, 107 (2017), 3722-3759.

Mulalic, Ismir, Jos N. Van Ommeren, and Ninette Pilegaard, "Wages and Commuting: Quasi-natural Experiments' Evidence from Firms that Relocate," Economic Journal, 124 (2014), 1086-1105.

Olivetti, Claudia, and Barbara Petrongolo, "The Evolution of Gender Gaps in Industrialized Countries," Annual Review of Economics, 8 (2016), 405-434.

Petrongolo, Barbara, and Maddalena Ronchi, "Gender Gaps and the Structure of Local Labor Markets," Labour Economics, 64 (2020), 101819.

Redding, Stephen J., and Matthew A. Turner, "Transportation Costs and the Spatial Organization of Economic Activity," in Handbook of Regional and Urban Economics, volume 5, Gilles Duranton, J. Vernon Henderson and William C. Strange, volume 5, eds. (Amsterdam: Elsevier, 2015), 1339-1398.

Roberts, Jennifer, Robert Hodgson, and Paul Dolan, "It's Driving Her Mad: Gender Differences in the Effects of Commuting on Psychological Health," Journal of Health Economics, 30 (2011), 1064-1076.

Rupert, Peter, Elena Stancanelli, and Etienne Wasmer, "Commuting, Wages and Bargaining Power," Annals of Economics and Statistics, 95/96 (2009), 201-220.

Small, Kenneth A., Urban Transportation Economics (Chur: Harwood, 1992). 
"Valuation of Travel Time," Economics of Transportation, 1 (2012), 2-14.

Small, Kenneth A., and Erik T. Verhoef, The Economics of Urban Transportation (London: Routledge, 2007).

Small, Kenneth A., Clifford Winston, and Jia Yan, "Uncovering the Distribution of Motorists' Preferences for Travel Time and Reliability," Econometrica, 73 (2005), 1367-1382.

Stutzer, Alois, and Bruno Frey, "Stress That Doesn't Pay: The Commuting Paradox," Scandinavian Journal of Economics, 110 (2008), 339-366.

Van Den Berg, Gerard J., "Nonstationarity in Job Search Theory," Review of Economic Studies, 57 (1990), 255-277.

Van Den Berg, Gerard J., and Cees Gorter, "Job Search and Commuting Time," Journal of Business and Economic Statistics, 15 (1997), 269-281.

Van Ommeren, Jos N., and Mogens Fosgerau, "Workers' Marginal Costs of Commuting," Journal of Urban Economics, 65 (2009), 38-47.

Van Ommeren, Jos N., Gerard J. Van Den Berg, and Cees Gorter, "Estimating the Marginal Willingness to Pay for Commuting," Journal of Regional Science, 40 (2000), 541-563.

Venn, Danielle, "Eligibility Criteria for Unemployment Benefits: Quantitative Indicators for OECD and EU Countries," OECD Social, Employment and Migration Working Papers 131, 2012.

Wiswall, Matthew, and Basit Zafar, "Preference for the Workplace, Investment in Human Capital, and Gender," Quarterly Journal of Economics, 133 (2017), 457-507. 